Article

\title{
New Oxidovanadium(IV) Complexes with 2,2'-bipyridine and 1,10-phenathroline Ligands: Synthesis, Structure and High Catalytic Activity in Oxidations of Alkanes and Alcohols with Peroxides
}

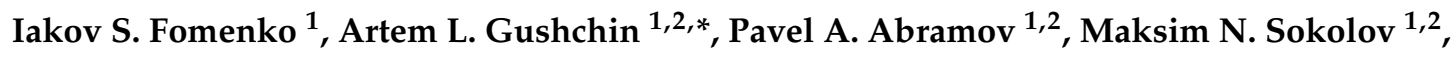 \\ Lidia S. Shul'pina ${ }^{3}\left(\mathbb{D}\right.$, Nikolay S. Ikonnikov ${ }^{3}$, Maxim L. Kuznetsov ${ }^{4}$ (D, \\ Armando J. L. Pombeiro ${ }^{4}$, Yuriy N. Kozlov ${ }^{5,6}$ and Georgiy B. Shul'pin ${ }^{5,6,7, *}$ \\ 1 Nikolaev Institute of Inorganic Chemistry, Siberian Branch of Russian Academy of Sciences, Prospekt Acad. \\ Lavrentieva, dom 3, 630090 Novosibirsk, Russia; fomenko@niic.nsc.ru (I.S.F.); abramov@niic.nsc.ru (P.A.A.); \\ caesar@niic.nsc.ru (M.N.S.) \\ 2 Novosibirsk State University, ul. Pirogova, dom 2, 630090 Novosibirsk, Russia \\ 3 Nesmeyanov Institute of Organoelement Compounds, Russian Academy of Sciences, ul. Vavilova, dom 28, \\ 119991 Moscow, Russia; shulpina@ineos.ac.ru (L.S.S.); ikonns@ineos.ac.ru (N.S.I.) \\ 4 Centro de Química Estrutural, Instituto Superior Técnico, Universidade de Lisboa, Avenida Rovisco Pais, \\ 1049-001 Lisboa, Portugal; max@mail.ist.utl.pt (M.L.K.); pombeiro@tecnico.ulisboa.pt (A.J.L.P.) \\ 5 Semenov Institute of Chemical Physics, Department of Dynamics of Chemical and Biological Processes, \\ Russian Academy of Sciences, ul. Kosygina, dom 4, 119991 Moscow, Russia; yunkoz@mail.ru \\ 6 Chair of Chemistry and Physics, Plekhanov Russian University of Economics, Stremyannyi pereulok, \\ dom 36, 117997 Moscow, Russia \\ 7 RussiaPeople's Friendship University of Russia, ul. Miklukho-Maklaya, dom 6, 117198 Moscow, Russia \\ * Correspondence: gushchin@niic.nsc.ru (A.L.G.); shulpin@chph.ras.ru or gbsh@mail.ru (G.B.S.); \\ Tel.: +7-495-939-7317 (G.B.S.)
}

Received: 24 January 2019; Accepted: 9 February 2019; Published: 26 February 2019

\begin{abstract}
Reactions of $\left[\mathrm{VCl}_{3}(\text { thf })_{3}\right]$ or $\mathrm{VBr}_{3}$ with 2,2'-bipyridine (bpy) or 1,10-phenanthroline (phen) in a 1:1 molar ratio in air under solventothermal conditions has afforded polymeric oxidovanadium(IV) four complexes 1-4 of a general formula $\left[\mathrm{VO}(\mathrm{L}) \mathrm{X}_{2}\right]_{\mathrm{n}}(\mathrm{L}=\mathrm{bpy}$, phen and $\mathrm{X}=\mathrm{Cl}, \mathrm{Br})$. Monomeric complex $\left[\mathrm{VO}(\mathrm{DMF})(\mathrm{phen}) \mathrm{Br}_{2}\right](\mathbf{4 a})$ has been obtained by the treatment of compound 4 with DMF. The complexes were characterized by IR spectroscopy and elemental analysis. The crystal structures of 3 and $4 \mathbf{a}$ were determined by an X-ray diffraction (XRD) analysis. The $\left\{\mathrm{VOBr}_{2}(\mathrm{bpy})\right\}$ fragments in 3 form infinite chains due to the $\mathrm{V}=\mathrm{O} \ldots \mathrm{V}$ interactions. The vanadium atom has a distorted octahedral coordination environment. Complexes 1-4 have been tested as catalysts in the homogeneous oxidation of alkanes (to produce corresponding alkyl hydroperoxides which can be easily reduced to alcohols by $\mathrm{PPh}_{3}$ ) and alcohols (to corresponding ketones) with $\mathrm{H}_{2} \mathrm{O}_{2}$ or tert-butyl hydroperoxide in $\mathrm{MeCN}$. Compound $\mathbf{1}$ exhibited the highest activity. The mechanism of alkane oxidation was established using experimental selectivity and kinetic data and theoretical DFT calculations. The mechanism is of the Fenton type involving the generation of $\mathrm{HO}^{\bullet}$ radicals.
\end{abstract}

Keywords: oxidovanadium(IV) complexes; heterocyclic diimines; alkanes; hydrogen peroxide; alkyl hydroperoxides; DFT calculations; reaction mechanism; Fenton mechanism

\section{Introduction}

Many organic reactions catalyzed by metal complexes have been reported in the recent years. Organic and inorganic peroxides and especially hydrogen peroxide are widely employed for the oxidation 
of various organic compounds. Alkanes are also among these organic substrates, although saturated hydrocarbons exhibit very high inertness in reactions in solutions under mild conditions [1-8].

The reactions of alkanes (as well as alcohols containing $\mathrm{C}-\mathrm{H}$ bonds) occur with the intermediate formation of free $\mathrm{O}$ - and $\mathrm{C}$-centered radicals. The latter easily reacts with molecular oxygen if the reaction is carried out in air. Finally, less stable (alkyl hydroperoxides) or stable (ketones) derivatives are produced $[9,10]$. The typical role of a metal complex in such transformations is to generate active radicals that attack $\mathrm{C}-\mathrm{H}$ bonds as well as to participate in various redox processes leading, finally, to the formation of stable products. Metal complexes with redox-active ligands have attracted considerable interest for use in the multi-electron activation of small molecules and in redox-based catalytic reactions [11-17].

Redox-active ligands have more energetically accessible levels for reduction or oxidation. As a result, either exclusively ligand-centered redox processes can occur, with the metal center remaining in the same oxidation state, or both the ligand and metal change their oxidation state in a synergistic fashion, creating ambiguity about the electronic state of both the metal and ligand.

Various vanadium derivatives are known to catalyze the oxidations of organic compounds with inorganic and organic peroxides (see reviews [18,19] and original papers [20-22]). Most oxidovanadium(IV) complexes have monomeric structures with an octahedral or square-pyramidal coordination geometry of vanadium [23-32]. Polynuclear linear chain structures $(\{V=\mathrm{O} \ldots \mathrm{V}=\mathrm{O} \ldots\})$, where vanadium is coordinated by a terminal oxygen atom $(\mathrm{V}=\mathrm{O})$ of an adjacent molecule to complete the octahedral geometry, are much less common. Most of them belong to oxidovanadium(IV) complexes with tetradentate Schiff base ligands [33-39].

In 1993, Shul'pin and coworkers discovered a highly efficient system for the oxidation of hydrocarbons consisting of the combination of a vanadate anion and pyrazine-2-carboxylic acid [40,41]. Later, this system, which catalyzes the transformation of alkanes into corresponding alkyl hydroperoxides with hydrogen peroxide in an acetonitrile solution, was investigated in detail [42-62]. Very recently, we have reported the synthesis of monomeric square-pyramidal oxidovanadium(IV) complex ([ $\mathrm{VOCl}_{2}(\mathrm{dpp}$-bian)]) with the redox-active bis[N-(2,6-diisopropylphenyl)imino]acenaphthene ligand (dpp-bian). The complex demonstrated a high catalytic activity towards alkane oxygenation by $\mathrm{H}_{2} \mathrm{O}_{2}$ under mild conditions [63]. Expanding that work, herein, we carried out reactions of $\left[\mathrm{VCl}_{3}(\mathrm{thf})_{3}\right.$ ] or $\mathrm{VBr}_{3}$ with heterocyclic diimines such as 2,2'-bipyridine and 1,10-phenanthroline to yield polymeric oxidovanadium(IV) complexes $\left[\mathrm{VO}(\mathrm{L}) \mathrm{X}_{2}\right]_{\mathrm{n}}(\mathrm{L}=$ bpy, phen and $\mathrm{X}=\mathrm{Cl}, \mathrm{Br})$ and studied their catalytic properties in alkane and alcohol oxidation reactions with peroxides.

\section{Results and Discussion}

\subsection{Synthesis and Characterization of Compounds $\mathbf{1 - 4 a}$}

Solventothermal conditions were applied for the synthesis of oxidovanadium(IV) complexes 1-4a. Vanadium trichloride adduct with tetrahydrofuran $\left(\left[\mathrm{VCl}_{3}(\mathrm{thf})_{3}\right]\right)$ and vanadium tribromide $\left(\mathrm{VBr}_{3}\right)$ were used as starting compounds which were oxidized during the reaction in air to give the $\mathrm{V}=\mathrm{O}$ moiety (Scheme 1). This synthetic procedure was previously applied for the synthesis of other oxidovanadium(IV) complexes with chiral dehydrophenanthroline and diazofluorene ligands as well as with the redox-active bis(N-(2,6-diisopropylphenyl)imino)acenaphthene (dpp-bian) ligand [25,63]. The reactions of the corresponding vanadium precursor and 2,2'-bipyridine (bpy) or 1,10-phenanthroline (phen) in a 1:1 molar ratio resulted in microcrystalline products in yields ranging from moderate to high.

The IR spectra of the complexes 1-4a show a strong V = O stretching band around $880-890 \mathrm{~cm}^{-1}$ which is typical for linear chain $\mathrm{V}=\mathrm{O} \ldots \mathrm{V}=\mathrm{O}$ polymeric structures [34-39] This band is significantly blue-shifted in the IR spectra of monomeric oxidovanadium complexes [63-66]. A ferromagnetic intermolecular interaction between the molecules in the chains of polymeric oxidovanadium(IV) complexes with tetradentate Schiff base ligands have been found [39]. 


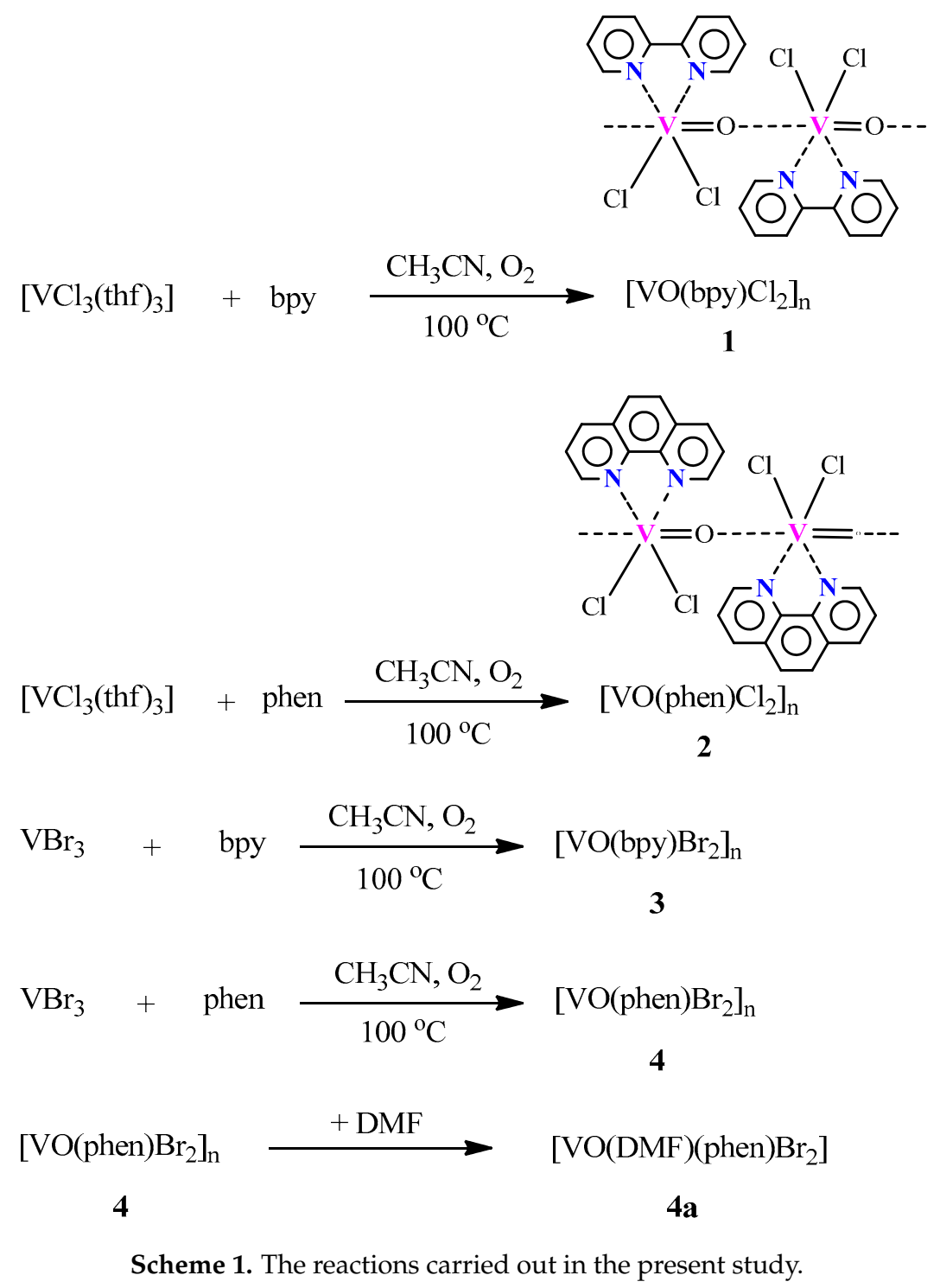

\subsection{Crystal Structures of $\mathbf{3}$ and $\mathbf{4 a}$}

Of the five products, $1,2,3,4$ and $4 \mathbf{a}$, only the green crystals of $\mathbf{3}$ and $\mathbf{4 a}$ obtained directly from the reaction mixture were of sufficient quality for X-ray diffraction (Table 1). Compound 3 forms a 1D-polymeric structure (Figure 1). The relevant bond distances are listed in Table 2. Vanadium is octahedrally coordinated by two nitrogen atoms of the chelating bpy ligand, as well as by two bromine atoms that lie in the plane of the bpy ligand and the oxygen atom from the vanadyl group, which is located perpendicular to the plane. The distorted octahedral environment is completed by the oxygen atom of the vanadyl group of the neighboring $\left\{\operatorname{VOBr}_{2}(\mathrm{bpy})\right\}$ fragment. Thus, the $\left\{\mathrm{VOBr}_{2}(\mathrm{bpy})\right\}$ fragments in 3 form infinite chains due to the $V=O \ldots V$ interactions (Figure 2). Based on the data of IR spectroscopy, we assume a similar structure for the remaining compounds $(\mathbf{1}, \mathbf{2}$ and $\mathbf{4})$.

The $\mathrm{V}=\mathrm{O}$ distance $(1.617(5) \AA)$ is longer and the $\mathrm{V}$. . . O distance $(2.123(5)-2.125(5) \AA)$ is shorter than those of the polymeric [VO(5- $\mathrm{NO}_{2}$ sal-meso-stien)] (1.599(3) and 2.437(3) $\AA$, respectively) [39] and [VO\{3-EtOsal-(R,R)-2,4-ptn\}] (1.617(6) and 2.290(6) $\AA$, respectively) [67] complexes with tetradentate Schiff base ligands.

Polymeric compounds 1-4 are insoluble in non-coordinating solvents and soluble in coordinating solvents such as DMF with the breaking up of the polymeric $\{\mathrm{V}=\mathrm{O} \ldots \mathrm{V}=\mathrm{O} \ldots\}$ structure and the excision of monomeric links. Single crystals of $\left[\mathrm{VO}(\mathrm{DMF})(\mathrm{phen}) \mathrm{Br}_{2}\right](\mathbf{4 a})$ were obtained by the treatment of 4 with DMF. An X-ray analysis of 4 a shows a monomeric structure with an octahedral 
coordination environment around vanadium, completed with a coordinated DMF molecule (Figure 3). The main geometric parameters of $\mathbf{4 a}$ are summarized in Table 2.

Table 1. A summary of the crystal data for compounds 3 and $\mathbf{4 a}$.

\begin{tabular}{|c|c|c|}
\hline & 3 & $4 \mathbf{a}$ \\
\hline \multicolumn{3}{|c|}{ Crystal Data } \\
\hline Chemical formula & $\mathrm{C}_{10} \mathrm{H}_{8} \mathrm{Br}_{2} \mathrm{~N}_{2} \mathrm{OV}$ & $\mathrm{C}_{15} \mathrm{H}_{15} \mathrm{Br}_{2} \mathrm{~N}_{3} \mathrm{O}_{2} \mathrm{~V}$ \\
\hline$M_{\mathrm{r}}$ & 382.94 & 480.06 \\
\hline Crystal system, space group & Monoclinic, $P 2_{1}$ & Monoclinic, $P 2_{1} / n$ \\
\hline Temperature $(\mathrm{K})$ & 130 & 150 \\
\hline$a, b, c(\AA)$ & $7.4626(3), 17.5643(7), 9.3510(4)$ & $7.1041(6), 14.0723(9), 17.2455(12)$ \\
\hline$\beta\left({ }^{\circ}\right)$ & $92.037(4)$ & $90.614(3)$ \\
\hline$V\left(\AA^{3}\right)$ & $1224.91(9)$ & $1724.0(2)$ \\
\hline$\mu\left(\mathrm{mm}^{-1}\right)$ & 7.31 & 5.22 \\
\hline \multirow[t]{2}{*}{ Crystal size (mm) } & $0.25 \times 0.06 \times 0.06$ & $0.10 \times 0.06 \times 0.05$ \\
\hline & Data collection & \\
\hline Diffractometer & New Xcalibur, AtlasS2 & Bruker Apex Duo \\
\hline \multirow{3}{*}{ Absorption correction } & Multi-scan CrysAlis PRO 1.171.38.41 (Rigaku & \\
\hline & $\begin{array}{l}\text { Oxford Diffraction, 2015) Empirical } \\
\text { absorption correction using spherical } \\
\text { harmonics, implemented in SCALE3 }\end{array}$ & \multirow[t]{2}{*}{$\begin{array}{l}\text { Multi-scan SADABS } \\
\text { (Bruker-AXS, 2004) }\end{array}$} \\
\hline & ABSPACK scaling algorithm. & \\
\hline$T_{\min }, T_{\max }$ & $0.739,1000$ & $0.545,0.642$ \\
\hline
\end{tabular}

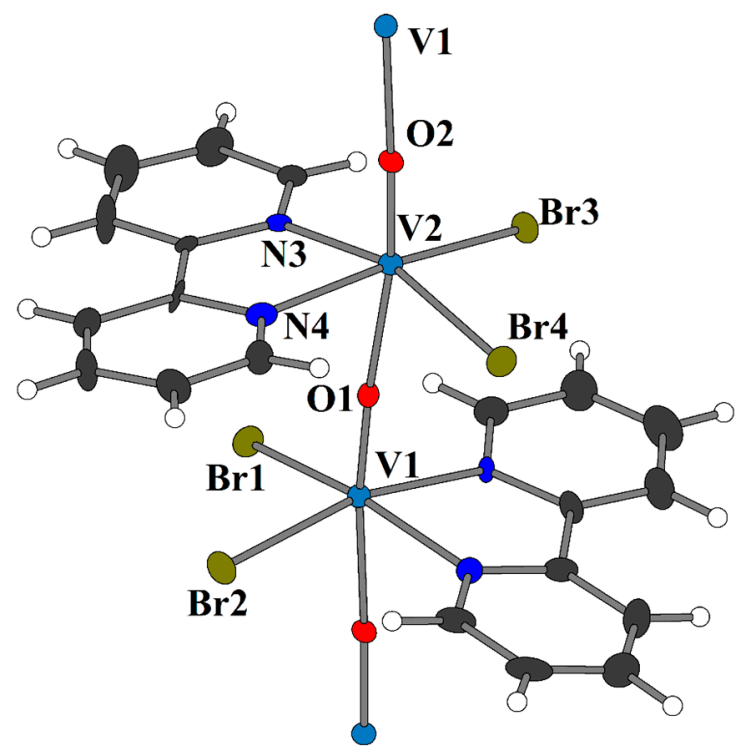

Figure 1. The structure of complex 3.

Table 2. The selected geometric parameters ( $\mathrm{A})$ for compounds $\mathbf{3}$ and $\mathbf{4 a}$.

\begin{tabular}{cccc}
\hline \multicolumn{4}{c}{ Compound 3 } \\
\hline $\mathrm{V} 1-\mathrm{O} 1$ & $1.617(5)$ & $\mathrm{V} 2-\mathrm{Br} 3$ & $2.4932(16)$ \\
$\mathrm{V} 1-\mathrm{O} 2$ & $2.123(5)$ & $\mathrm{V} 2-\mathrm{Br} 4$ & $2.4919(16)$ \\
$\mathrm{V} 1-\mathrm{Br} 1$ & $2.4944(16)$ & $\mathrm{N} 1-\mathrm{V} 1$ & $2.124(7)$ \\
\hline
\end{tabular}


Table 2. Cont.

\begin{tabular}{cccc}
\hline \multicolumn{5}{c}{ Compound 3 } \\
\hline $\mathrm{V} 1-\mathrm{Br} 2$ & $2.5028(16)$ & $\mathrm{N} 2-\mathrm{V} 1$ & $2.129(8)$ \\
$\mathrm{V} 2-\mathrm{O}{ }^{\mathrm{i}}$ & $2.125(5)$ & $\mathrm{N} 3-\mathrm{V} 2$ & $2.124(8)$ \\
$\mathrm{V} 2-\mathrm{O} 2$ & $1.617(5)$ & $\mathrm{N} 4-\mathrm{V} 2$ & $2.136(8)$ \\
\hline $\mathrm{V} 1-\mathrm{O} 1-\mathrm{V} 2{ }^{\mathrm{ii}}$ & $176.2(4)$ & $\mathrm{C} 10-\mathrm{N} 2-\mathrm{V} 1$ & $125.3(7)$ \\
$\mathrm{V} 2-\mathrm{O} 2-\mathrm{V} 1$ & $177.8(4)$ & $\mathrm{C} 11-\mathrm{N} 3-\mathrm{V} 2$ & $125.2(7)$ \\
$\mathrm{C} 1-\mathrm{N} 1-\mathrm{V} 1$ & $125.2(7)$ & $\mathrm{C} 15-\mathrm{N} 3-\mathrm{V} 2$ & $115.4(6)$ \\
$\mathrm{C} 5-\mathrm{N} 1-\mathrm{V} 1$ & $116.8(6)$ & $\mathrm{C} 16-\mathrm{N} 4-\mathrm{V} 2$ & $115.5(6)$ \\
$\mathrm{C} 6-\mathrm{N} 2-\mathrm{V} 1$ & $116.7(6)$ & $\mathrm{C} 20-\mathrm{N} 4-\mathrm{V} 2$ & $124.5(7)$ \\
\hline \multicolumn{5}{c}{ Compound 4a } \\
\hline $\mathrm{O} 1-\mathrm{V} 2$ & $1.600(3)$ & $\mathrm{N} 2-\mathrm{V} 2$ \\
$\mathrm{O} 2-\mathrm{V} 2$ & $1.996(3)$ & $\mathrm{Br} 1-\mathrm{V} 2$ & $2.121(3)$ \\
$\mathrm{N} 1-\mathrm{V} 2$ & $2.296(3)$ & $\mathrm{Br} 2-\mathrm{V} 2$ & $2.5450(8)$ \\
\hline $\mathrm{C} 14-\mathrm{O} 2-\mathrm{V} 2$ & $129.3(3)$ & $\mathrm{C} 3-\mathrm{N} 2-\mathrm{V} 2$ \\
$\mathrm{C} 1-\mathrm{N} 1-\mathrm{V} 2$ & $129.6(2)$ & $\mathrm{C} 4-\mathrm{N} 2-\mathrm{V} 2$ & $117.8(3)$ \\
$\mathrm{C} 2-\mathrm{N} 1-\mathrm{V} 2$ & $112.6(3)$ & $123.2(3)$ \\
\hline \multicolumn{5}{c}{ Note. Symmetry code(s): (i) $x+1, y, z ;(\mathrm{ii}) x-1, y, z}$. \\
\end{tabular}

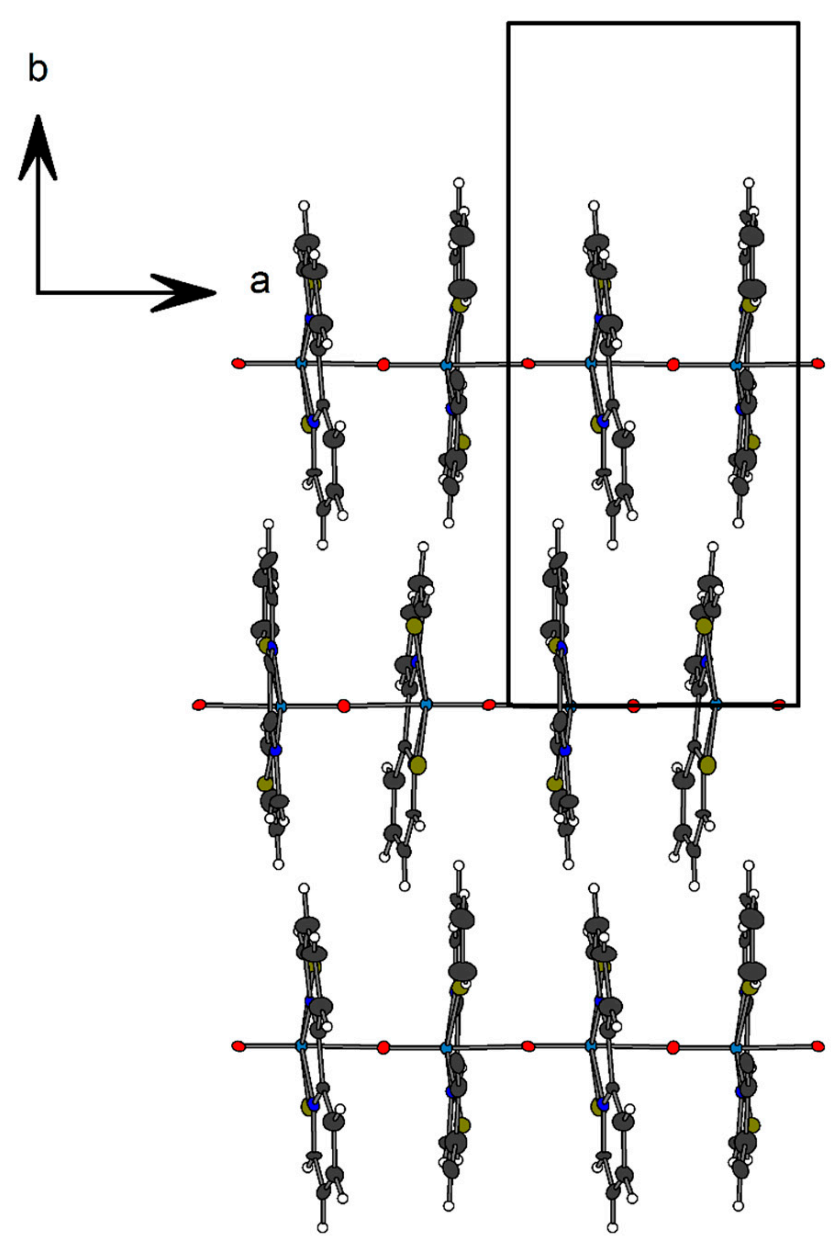

Figure 2. The crystal packing of complex 3. 


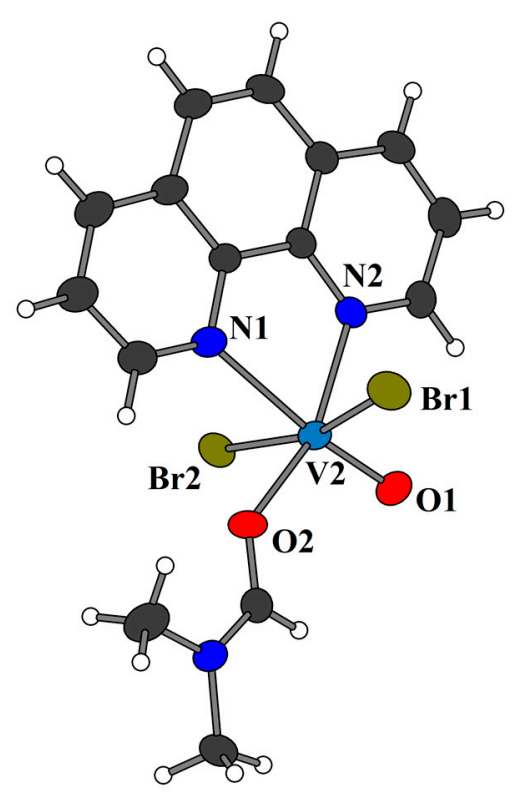

Figure 3. The molecular structure of $\left[\mathrm{VO}(\mathrm{DMF})(\mathrm{phen}) \mathrm{Br}_{2}\right](4 a)$.

\subsection{Oxidation of Alkanes with Peroxides Catalyzed by Complexes 1-4}

Systems based on metal complexes are known to catalyze hydrocarbon and alcohol oxygenations, i.e., replacing $\mathrm{H}$ atoms by oxygen. The chloride complexes $\mathbf{1}$ and $\mathbf{2}$ prepared in this work exhibited a high catalytic activity in the oxidation of alkanes with $\mathrm{H}_{2} \mathrm{O}_{2}$ in an acetonitrile solution. Thus, stirring at $20^{\circ} \mathrm{C}$ a solution of $2\left(5 \times 10^{-4} \mathrm{M}\right)$, cyclohexane $(0.46 \mathrm{M}), \mathrm{H}_{2} \mathrm{O}_{2}$ (aqueous, $2 \mathrm{M}$ ) after $150 \mathrm{~h}$ gave 0.011 $\mathrm{M}$ of cyclohexanone and $0.041 \mathrm{M}$ of cyclohexanol (analysis after the reduction of the solution with $\left.\mathrm{PPh}_{3}\right)$. An analogous reaction catalyzed by complex $1\left(5 \times 10^{-4} \mathrm{M}\right)$ afforded cyclohexanone $(0.015 \mathrm{M})$ and cyclohexanol $(0.12 \mathrm{M})$. At a higher temperature $\left(40^{\circ} \mathrm{C}\right)$, the reactions proceeded faster: After $6 \mathrm{~h}$, yields of cyclohexanone and cyclohexanol were $0.01 \mathrm{M}$ and $0.112 \mathrm{M}$, respectively, in the case of catalyst 2. Complex 1 turned out to be more efficient, affording $0.02 \mathrm{M}$ and $0.16 \mathrm{M}$ of cyclohexanone and cyclohexanol, respectively, after the reduction of the solution with $\mathrm{PPh}_{3}$ (compare Figures 4 and 5). This activity is comparable with that found by us previously for the other vanadium complexes in the alkane oxidations with peroxides [40-63].

The oxidation reactions catalyzed by compound 1 have been studied in more detail. Figure 4 clearly demonstrates that the reduction of the reaction solution with $\mathrm{PPh}_{3}$ gives rise to a higher concentration of cyclohexanol and a decrease of cyclohexanone concentration (compare Graphs A and B). These changes indicate (the so-called Shul'pin method [68-82]) that alkyl hydroperoxide is formed in the course of the oxidation. For the transfomations of cyclohexane, see a Scheme in Figure 4A.

The dependence of the initial oxidation rate $W_{0}$ on the initial concentration of catalyst 1 is shown in Figure 6. The curve of dependence of the initial oxidation rate in the case of catalysis by complex $\mathbf{1}$ is approaching a plateau at a cyclohexane concentration of $>0.46 \mathrm{M}$ (Figure 7). The rate at $[\mathrm{CyH}]_{0} \approx 0.2 \mathrm{M}$ is approximately equal to half of the maximum rate.

The competitive oxidation of cyclohexane and acetonitrile (solvent) in the presence of complex 1 is demonstrated in Figure 7. The dependence of the oxidation rate in the case of catalyst $\mathbf{1}$ (Figure 8) is in a good agreement with the Arrhenius Equation $\left(E_{\mathrm{a}}=20 \pm 2 \mathrm{kcal} / \mathrm{mol}\right)$ and with the value calculated in accordance with the model shown below in Scheme $2\left(\Delta H^{\prime}=19.6 \mathrm{kcal} / \mathrm{mol}\right)$. The proposed model is also in agreement with the experimental data: In both cases, the first order of the oxidation relative catalyst concentration was found (see Figure 6). 

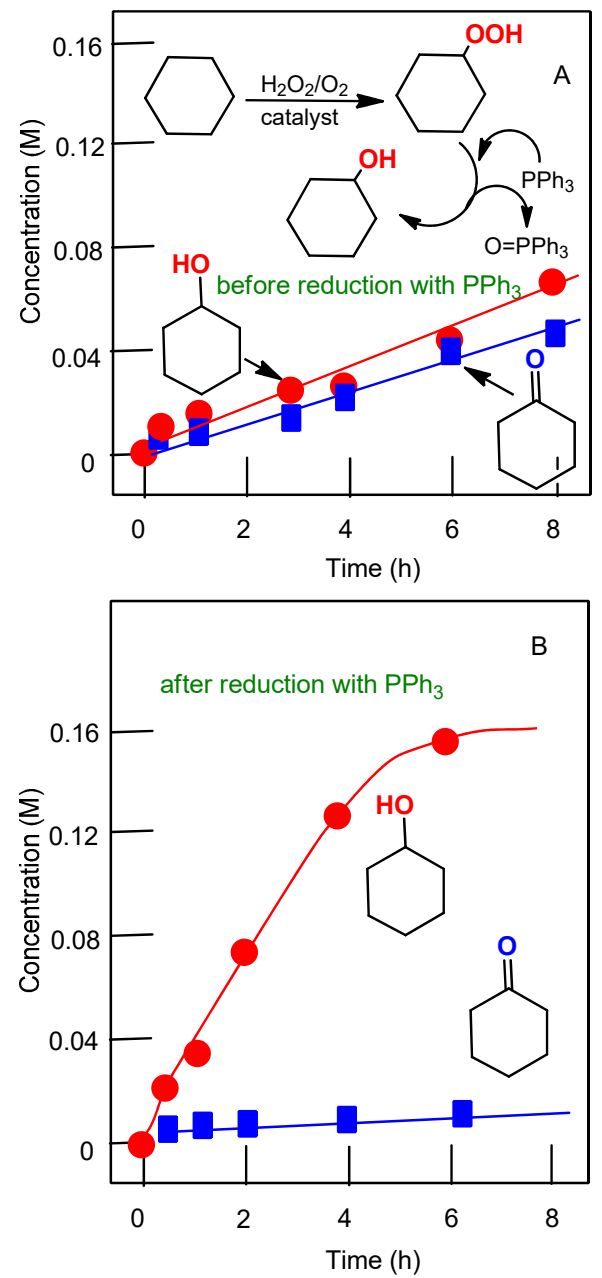

Figure 4. The accumulation of cyclohexanol and cyclohexanone in the oxidation of cyclohexane $(0.46 \mathrm{M})$ with $\mathrm{H}_{2} \mathrm{O}_{2}(2.0 \mathrm{M})$ catalysed by complex $1\left(5 \times 10^{-4} \mathrm{M}\right)$ at $40^{\circ} \mathrm{C}$ : The concentrations of the products were measured by GC before (Graph A) and after (Graph B) the reduction of the reaction sample with solid $\mathrm{PPh}_{3}$.

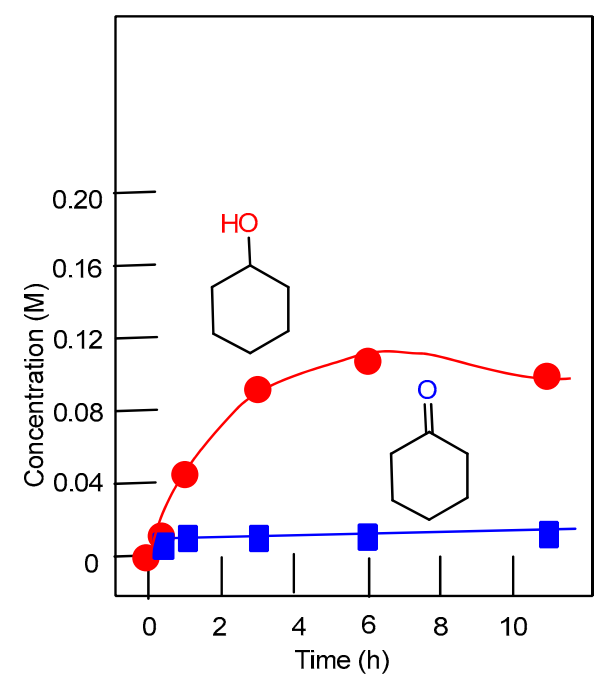

Figure 5. The accumulation of cyclohexanol and cyclohexanone in the oxidation of cyclohexane $(0.46 \mathrm{M})$ with $\mathrm{H}_{2} \mathrm{O}_{2}(2.0 \mathrm{M})$ catalysed by complex $2\left(5 \times 10^{-4} \mathrm{M}\right)$ at $40{ }^{\circ} \mathrm{C}$ : The concentrations of the products were measured by GC only after the reduction of the reaction sample with solid $\mathrm{PPh}_{3}$. 


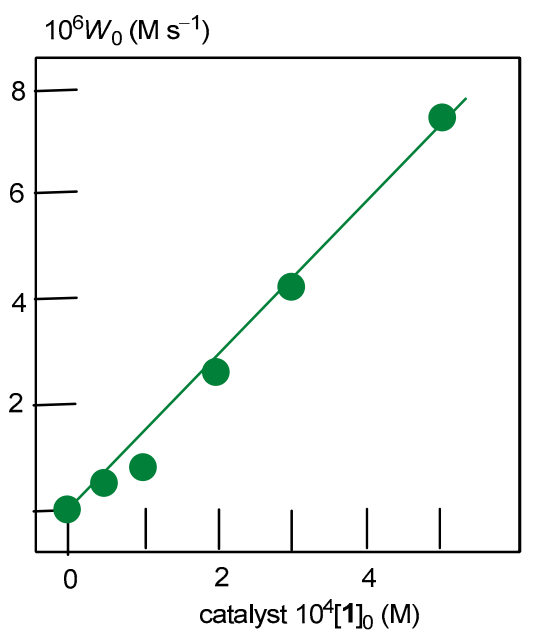

Figure 6. The dependence of the initial oxidation rate $W_{0}$ on the initial concentration of catalyst 1 in the oxidation of cyclohexane $(0.46 \mathrm{M})$ into cyclohexanol and cyclohexanone (a sum; after the reduction of the reaction mixture with $\left.\mathrm{PPh}_{3}\right)$ with $\mathrm{H}_{2} \mathrm{O}_{2}(2.0 \mathrm{M})$ catalysed by complex 1 at $40{ }^{\circ} \mathrm{C}$ : The concentrations of the products were measured by GC after the reduction of the reaction sample with solid $\mathrm{PPh}_{3}$.
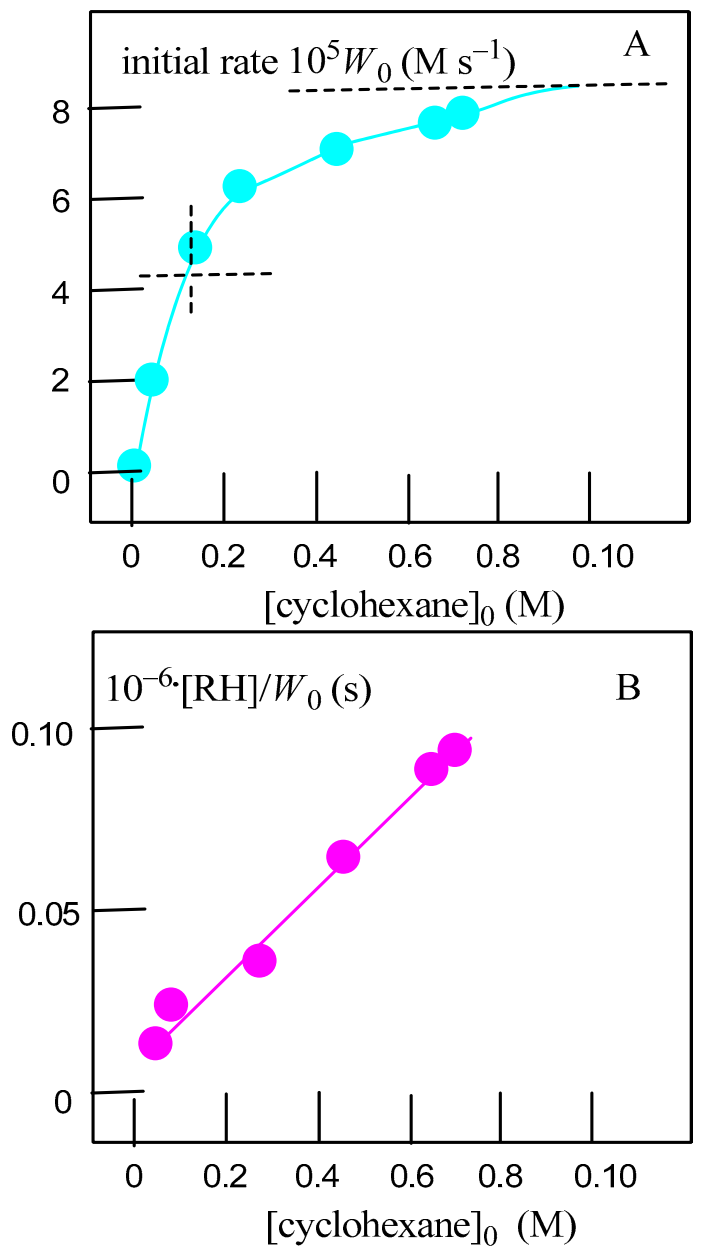

Figure 7. The dependence of the initial oxidation rate $W_{0}$ on the initial concentration of cyclohexane (Graph A) in the oxidation of cyclohexane into cyclohexanol and cyclohexanone (via the formation of cyclohexyl hydroperoxide) with $\mathrm{H}_{2} \mathrm{O}_{2}(2.0 \mathrm{M})$ catalysed by complex 1 . Graph B: the linearization of the curve depicted in Graph A. Conditions: catalyst $1\left(5 \times 10^{-4} \mathrm{M}\right), 40^{\circ} \mathrm{C}$. The concentrations of products were measured by GC only after the reduction of the reaction sample with solid $\mathrm{PPh}_{3}$. 


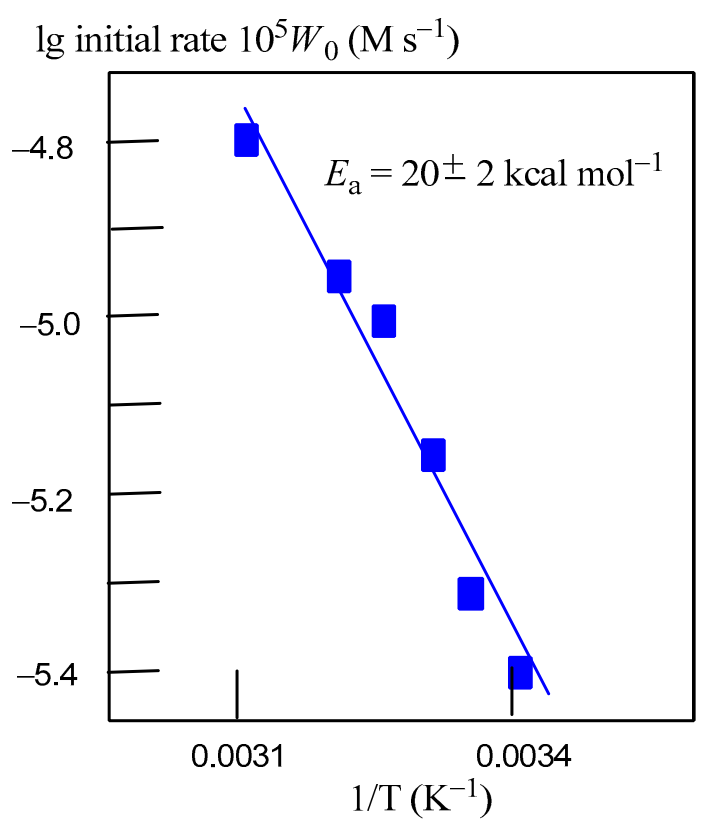

Figure 8. The Arrhenius dependence of the cyclohexane $(0.46 \mathrm{M})$ oxidation with $\mathrm{H}_{2} \mathrm{O}_{2}(50 \%, 2.0 \mathrm{M})$ catalysed by compound $1\left(5 \times 10^{-4} \mathrm{M}\right)$ in acetonitrile: The concentrations of the products were measured by GC after the reduction of the reaction sample with solid $\mathrm{PPh}_{3}$.

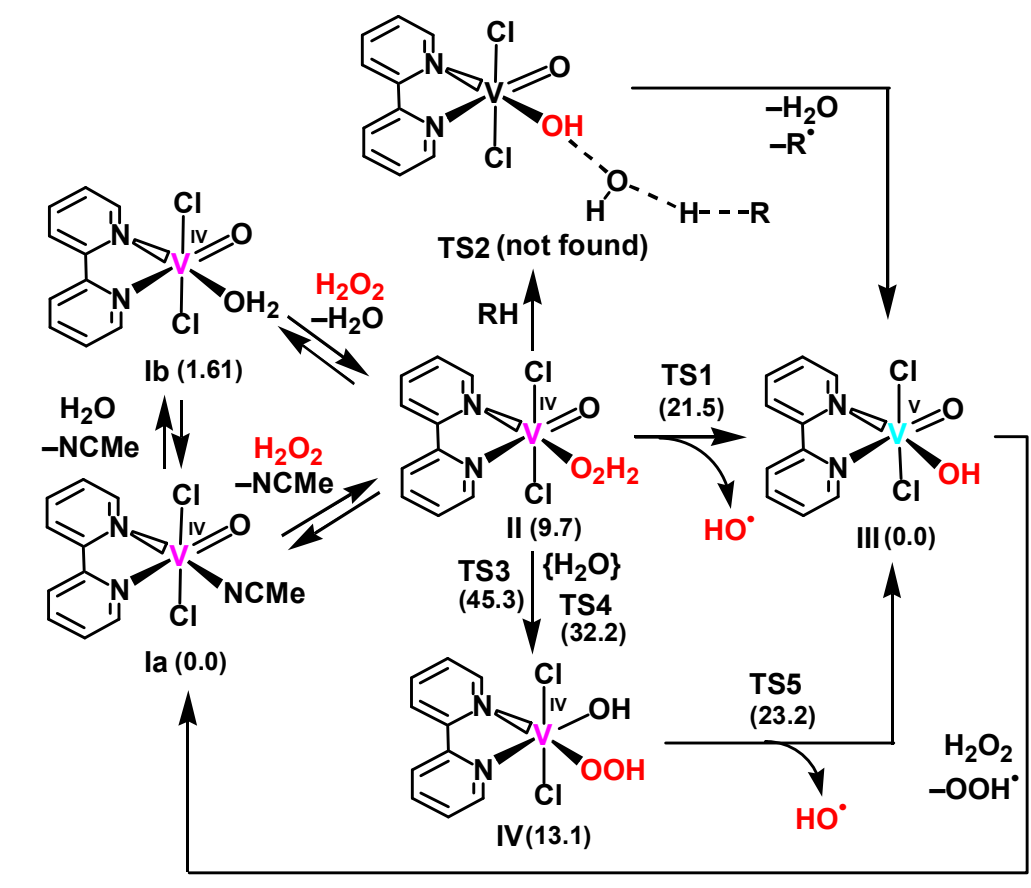

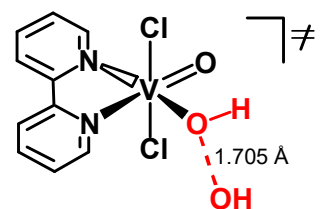

TS1

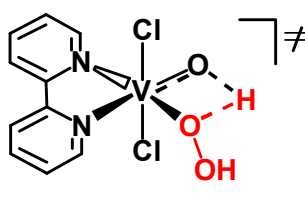

TS3

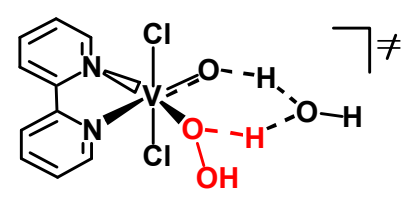

TS4

Scheme 2. The mechanism of the $\mathrm{HO}^{\bullet}$ generation from the $\mathrm{H}_{2} \mathrm{O}_{2}$ catalyzed by $\mathbf{I}$ (Gibbs free energies are indicated in parentheses relative to $\mathbf{I a}$ in $\mathrm{kcal} / \mathrm{mol}$ ). 
The bromide complexes 3 and 4 also catalyze the cyclohexane oxidation with $\mathrm{H}_{2} \mathrm{O}_{2}$; the corresponding kinetic curves of the product accumulation are presented in Figure 9. The dependence of the initial oxidation rate in the reaction catalyzed by complex 3 exhibits an approach to a plateau (see an analogous dependence in Figure 7).
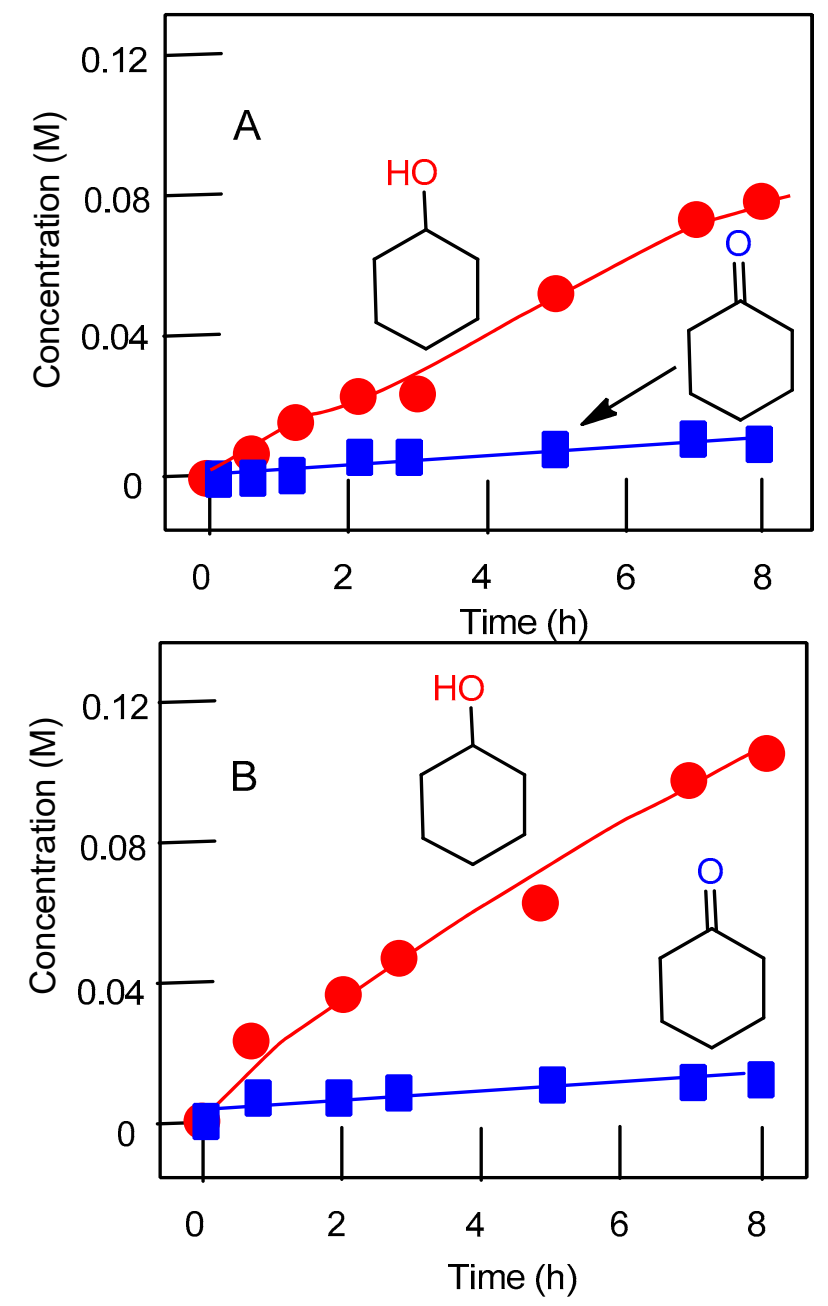

Figure 9. The kinetic curves for the oxidation of cyclohexane $(0.46 \mathrm{M})$ into cyclohexanol and cyclohexanone with $\mathrm{H}_{2} \mathrm{O}_{2}(2.0 \mathrm{M})$ catalysed by complexes 3 (Graph A) or 4 (Graph B; the concentration of both catalysts was $5 \times 10^{-4} \mathrm{M}$ ). Conditions: $40^{\circ} \mathrm{C}$. The concentrations of the products were measured by GC only after the reduction of the reaction sample with solid $\mathrm{PPh}_{3}$.

The experiments shown in Figures 4 and 5 indicate that the catalytic activity of complex 2 is practically equal to that of compound $1\left(W_{0} 1.1 \times 10^{-5}\right.$ and $1.0 \times 10^{-5} \mathrm{M} \mathrm{s}^{-1}$, respectively). The activities of complexes 3 and 4 are a bit lower $\left(W_{0} 2.8 \times 10^{-6}\right.$ and $4.2 \times 10^{-6} \mathrm{M} \mathrm{s}^{-1}$, respectively).

Compound 2 catalyzes the oxidation of cyclohexene $(0.4 \mathrm{M})$ with $\mathrm{H}_{2} \mathrm{O}_{2}(0.32 \mathrm{~mL})$ at $40{ }^{\circ} \mathrm{C}$ to afford, after $1 \mathrm{~h}$, cyclohex-2-ene-1-ol (0.053 M) and cyclohex-2-one-1 (0.01 M). Cyclohexanol (0.5 M) was oxidized by tert-butyl hydroperoxide at $50{ }^{\circ} \mathrm{C}$ to produce cyclohexanone $(0.23 \mathrm{M})$ after $4 \mathrm{~h}$.

We determined the selectivity parameters for the oxidation of certain alkanes (n-heptane, methylcyclohexane and cis-1,2-dimethylcyclohexane catalyzed by complexes 1-4 (Table 3). The oxygenation of cis-1,2-dimethylcyclohexane with $\mathrm{H}_{2} \mathrm{O}_{2}$ catalysed by complex 3 gave corresponding isomeric tertiary alcohols in a trans/cis ratio of 0.8 . These data as well as the character of dependence of the initial cyclohexane oxidation rate on the initial hydrocarbon concentration (approaching a plateau at [cyclohexane $]_{0}>0.3 \mathrm{M}$ ) indicate that the reaction occurs with the participation of hydroxyl radicals and that alkyl hydroperoxides are formed as the main primary products. 
Table 3. The selectivity parameters for the oxidation of certain alkanes with $\mathrm{H}_{2} \mathrm{O}_{2}$.

\begin{tabular}{ccccc}
\hline \multicolumn{2}{c}{$n$-Heptane } & & $\mathbf{M e C H}^{\circ}$ & 1,2-cis-DMCH \\
\hline Entry & Catalyst & $\mathbf{C ( 1 ) : C ( 2 ) : C ( 3 ) : C ( 4 )}$ & $\mathbf{1}^{\circ}: 2^{\circ}: 3^{\circ}$ & trans/cis \\
\hline 1 & $\mathbf{1}$ & $1.0: 5.6: 5.8: 5.2$ & $1.0: 5.9: 16.0$ & 0.84 \\
2 & $\mathbf{2}$ & $1.0: 5.6: 5.6: 5.2$ & $1.0: 5.3: 17.5$ & 0.7 \\
3 & $\mathbf{3}$ & $1.0: 5.7: 6.2: 5.6$ & $1.0: 5.0: 12.6$ & 0.8 \\
4 & $\mathbf{4}$ & $1.0: 5.9: 6.2: 5.9$ & $1.0: 5.4: 12.9$ & 0.9 \\
\hline
\end{tabular}

We can assume that the alkane oxidation is induced with an intermediate species generated in the catalytic decomposition of hydrogen peroxide. The dependence of the rate of cyclohexyl hydroperoxide $(\mathrm{ROOH})$ formation on the initial concentration of cyclohexane ( $\mathrm{RH}$, see Figure 7 above) indicates a competition between cyclohexane and acetonitrile for the catalytically active species. The selectivity parameters measured in the oxidation of linear and branched alkanes (Table 3) are close to the parameters typical for the reactions of alkanes with hydroxyl radicals $[83,84]$. Taking this fact into account, we can consider the simplest scheme of the concurrent oxidation:

$$
\begin{gathered}
\mathrm{H}_{2} \mathrm{O}_{2}+\mathrm{Cat} \rightarrow \mathrm{HO} \bullet \mathrm{W}_{\mathrm{i}} \\
\mathrm{HO} \bullet+\mathrm{RH} \rightarrow \mathrm{R} \bullet \rightarrow \rightarrow \mathrm{ROOH} k_{1} \\
\mathrm{HO} \bullet+\mathrm{CH}_{3} \mathrm{CN} \rightarrow \rightarrow \text { products } k_{2}
\end{gathered}
$$

Here, $W_{\mathrm{i}}$ is the rate of generation of hydroxyl radicals, formed in the process of catalytic $\mathrm{H}_{2} \mathrm{O}_{2}$ decomposition; (1) and (2) are the transformations of $\mathrm{RH}$ into $\mathrm{ROOH}$ and $\mathrm{CH}_{3} \mathrm{CN}$ into products and where the rate limiting steps are the interactions of $\mathrm{HO} \bullet$ with $\mathrm{RH}\left(k_{1}\right)$ and with $\mathrm{CH}_{3} \mathrm{CN}\left(k_{2}\right)$.

Assuming that the concentration of hydroxyl radicals is quasi-stationary during the reaction, we can obtain the term for the initial rate of $\mathrm{ROOH}$ formation:

$$
(\mathrm{d}[\mathrm{ROOH}] / \mathrm{d} t)_{0}=W_{\mathrm{i}} /\left(1+k_{2}\left[\mathrm{CH}_{3} \mathrm{CN}\right] / k_{1}[\mathrm{RH}]\right)
$$

In order to analyze the experimental data shown in Figure 7, let us transform Equation (3) into Equation (4):

$$
[\mathrm{RH}] /\left(\mathrm{d}[\mathrm{ROOH} / \mathrm{dt})_{0}=\left(\left(\mathrm{k}_{2} / \mathrm{k}_{1}\right)\left[\mathrm{CH}_{3} \mathrm{CN}\right]+[\mathrm{RH}]\right)\left(1 / \mathrm{W}_{\mathrm{i}}\right)\right.
$$

The linear anamorphosis in coordinates

$$
[\mathrm{RH}] /\left(\mathrm{d}[\mathrm{ROOH} / \mathrm{dt})_{0}-[\mathrm{RH}]\right.
$$

of the experimental dependence shown in Figure 7A is presented in Figure 7B. The analysis of this dependence leads to conclusions that: 1 ) the experimental data of Figure 7 satisfy the proposed model $\left.\left\{W_{i}, 1,2\right\} ; 2\right)$ the segment cut on the $y$-axis

$$
\left(1 / \mathrm{W}_{\mathrm{i}}\right)\left(\mathrm{k}_{2} / \mathrm{k}_{1}\right)\left[\mathrm{CH}_{3} \mathrm{CN}\right]=0.014 \cdot 10^{6} \mathrm{~s}
$$

and 3) the tangent of the slope

$$
\left(1 / \mathrm{W}_{\mathrm{i}}\right)=0.128 \cdot 10^{6} \mathrm{M}^{-1} \mathrm{~s}
$$

Thus, for the conditions shown in Figure 7, the experimental parameters are $W_{\mathrm{i}}=8.10^{-6} \mathrm{M} \mathrm{s}^{-1}$ and $k_{2}\left[\mathrm{CH}_{3} \mathrm{CN}\right] / k_{1}=0.11 \mathrm{M}$. The latter ratio of rate constants is equal to the value obtained by some of us earlier for other hydroxyl radical generating systems [83,84]. 


\subsection{Theoretical Mechanistic Study}

With the aim to shed light on the mechanism of alkane oxidation with $\mathrm{H}_{2} \mathrm{O}_{2}$ catalyzed by the $\mathrm{V}(\mathrm{IV})$ complexes under study, DFT calculations have been performed for the monomeric form of $\mathbf{1}$ as a catalyst. In accordance with the experimental kinetic and selectivity data discussed above, the global reaction mechanism is radical one, involving the generation of the $\mathrm{HO}^{\bullet}$ species which then oxidize the alkane molecules $\mathrm{R}-\mathrm{H}$ to give, upon the hydrogen abstraction, the corresponding alkyl radicals $\mathrm{R}^{\bullet}$ (Scheme 3). The latter react with molecular oxygen, producing the alkylperoxo radicals $\mathrm{ROO}^{\bullet}$ and then the corresponding alkyl hydroperoxide $\mathrm{ROOH}$ experimentally detected by GC. In accordance with the kinetic studies, the rate limiting step of the whole process is the generation of the $\mathrm{HO}^{\bullet}$ radicals.

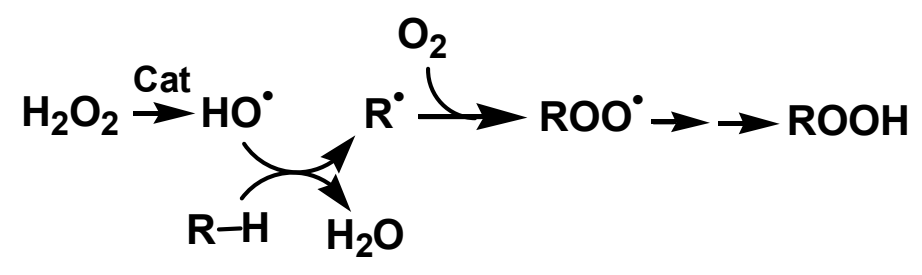

Scheme 3. The radical mechanism of the alkane oxidation with $\mathrm{H}_{2} \mathrm{O}_{2}$.

The experimental data demonstrate that the polymeric pre-catalyst $\mathbf{1}$ is not stable in a DMF solution, transforming to the mononuclear species, presumably $\left[\mathrm{V}(=\mathrm{O})(\mathrm{bpy})(\mathrm{DMF}) \mathrm{Cl}_{2}\right]$. Similarly, the easy solvolysis of $\mathbf{1}$ in acetonitrile or aqueous solutions is expected to give $\left[\mathrm{V}(=\mathrm{O})(\mathrm{bpy})\left(\mathrm{N} \equiv \mathrm{CMe} \mathrm{Cl}_{2}\right](\mathbf{I a})\right.$ or $\left[\mathrm{V}(=\mathrm{O})(\mathrm{bpy})\left(\mathrm{H}_{2} \mathrm{O}\right) \mathrm{Cl}_{2}\right](\mathbf{I b})$, respectively. Indeed, the calculations indicate that the transformations of $\mathbf{I}$ into $\mathbf{I a}$ or $\mathbf{I b}$ are exergonic by 5.2 or $2.0 \mathrm{kcal} / \mathrm{mol}$, correspondingly. The structures of four possible geometric isomers of $\mathbf{I b}$ were calculated (Figure 10), and the most stable isomer is that with two chloride ligands being in the trans-position.

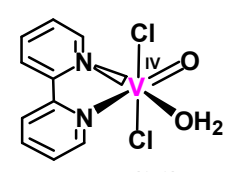

Ib (0.0)

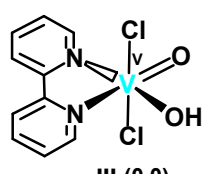

III (0.0)
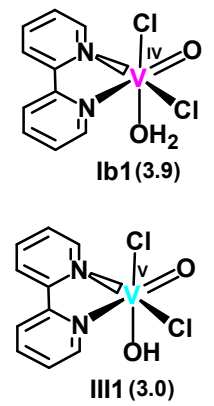
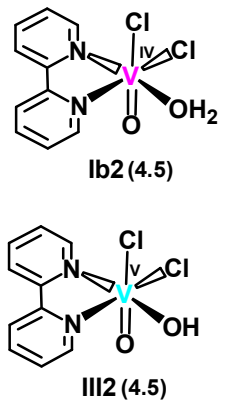
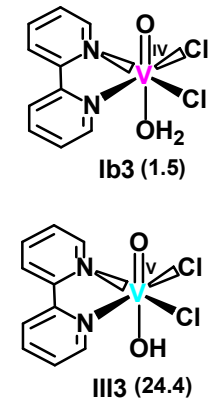

Figure 10. The calculated equilibrium structures of various geometrical isomers of complexes $\left[\mathrm{V}^{\mathrm{IV}}(=\mathrm{O})(\mathrm{bpy})\left(\mathrm{H}_{2} \mathrm{O}\right) \mathrm{Cl}_{2}\right]$ and $\left[\mathrm{V}^{\mathrm{V}}(=\mathrm{O})(\mathrm{bpy})(\mathrm{OH}) \mathrm{Cl}_{2}\right]$. (Gibbs free energies are indicated in parentheses in $\mathrm{kcal} / \mathrm{mol}$ relative to the most stable isomers $\mathbf{I b}$ and III.)

In the presence of hydrogen peroxide, the acetonitrile or water ligands in I can be replaced for $\mathrm{H}_{2} \mathrm{O}_{2}$ to give $\left[\mathrm{V}(=\mathrm{O})\left(\right.\right.$ bpy) $\left(\mathrm{H}_{2} \mathrm{O}_{2}\right) \mathrm{Cl}_{2}$ ] (II) (Scheme 2). Such a substitution is endergonic by 8.1-9.7 kcal/mol. The coordination of $\mathrm{H}_{2} \mathrm{O}_{2}$ to the $\mathrm{V}(\mathrm{IV})$ center tremendously activates this molecule towards the $\mathrm{O}-\mathrm{O}$ homolysis. Indeed, the energy of the homolytic $\mathrm{O}-\mathrm{O}$ bond cleavage in II leading to III and $\mathrm{HO}^{\bullet}$ is $-9.7 \mathrm{kcal} / \mathrm{mol}$, indicating that this process is exergonic. Meanwhile, the activation barrier for the $\mathrm{HO}^{\bullet}$ generation from II via TS1 is $11.8 \mathrm{kcal} / \mathrm{mol}$ (see Supplementary Materials). The overall activation barrier of the $\mathrm{HO}^{\bullet}$ formation relative to the most stable complex Ia is $21.5 \mathrm{kcal} / \mathrm{mol}$ in terms of $\Delta \mathrm{G}^{\neq}$and $19.6 \mathrm{kcal} / \mathrm{mol}$ in terms of $\Delta \mathrm{H}^{\neq}$. The latter value is in a good agreement with the experimentally obtained activation energy for this reaction catalyzed by complex $\mathbf{1}(20 \pm 2 \mathrm{kcal} / \mathrm{mol}$, see above Figure 8).

In principle, the formation of the alkyl radicals $\mathrm{R}^{\bullet}$ could occur in one step directly from II via TS2. This transition state should correspond to the simultaneous $\mathrm{O}-\mathrm{O}$ and $\mathrm{C}-\mathrm{H}$ bond cleavages and the 
$\mathrm{O}-\mathrm{H}$ bond formation. However, all attempts to locate TS2 failed, leading to TS1 and $\mathrm{C}_{6} \mathrm{H}_{12}$ situating at the second coordination sphere.

Another plausible pathway of the $\mathrm{HO}^{\bullet}$ generation includes the preliminary proton transfer in II from the coordinated $\mathrm{H}_{2} \mathrm{O}_{2}$ to the oxo ligand to give complex $\left[\mathrm{V}(\mathrm{OH})(\mathrm{bpy})(\mathrm{OOH}) \mathrm{Cl}_{2}\right]$ (IV). The following homolytic $\mathrm{O}-\mathrm{OH}$ bond cleavage in the hydroperoxo ligand produces $\mathrm{HO}^{\bullet}$ and III. Two possible transition states for the proton transfer were found, i.e., the 4-membered cyclic TS3 and the 6-membered cyclic TS4, with $\mathrm{H}_{2} \mathrm{O}$ molecule playing the role of a proton shuttle. However, the calculated activation energy for such an H-transfer is too high for both these TSs (45.3 and $32.2 \mathrm{kcal} / \mathrm{mol}$, respectively, relative to Ia). Thus, the calculations indicate that the simple Fenton mechanism is operating for the catalyst 1.

\section{Experimental Section}

\subsection{Computational Details}

The full geometry optimization of all structures and transition states (TSs) has been carried out at the DFT level of theory by using the M06 functional [85] with the help of the Gaussian 09 program package [86]. No symmetry operations were applied. The geometry optimization was carried out by using a relativistic Stuttgart pseudopotential which describes 10 core electron (MDF10) and the appropriate contracted basis set (8s7p6d1f)/[6s5p3d1f] [87] for the vanadium atom and the 6-311+ $\mathrm{G}^{* *}$ basis set for other atoms. This level of theory was successfully applied recently for the analysis of mechanisms of the V-catalyzed oxidation of alkanes with peroxides [88].

The Hessian matrix was calculated analytically for the optimized structures to prove the location of correct minima (no imaginary frequencies) or saddle points (only one imaginary frequency) and to estimate the thermodynamic parameters, with the latter calculated at $25^{\circ} \mathrm{C}$. The nature of all transition states was investigated by analysis of the vectors associated with the imaginary frequency and by the calculations of the intrinsic reaction coordinates (IRC) by using the method developed by Gonzalez and Schlegel [89-91].

The total energies corrected for solvent effects $E_{S}$ were estimated at the single-point calculations on the basis of gas-phase geometries using the polarizable continuum model in the CPCM version [92,93] with $\mathrm{CH}_{3} \mathrm{CN}$ as solvent. The UAKS model was applied for the molecular cavity, and dispersion, cavitation and repulsion terms were taken into account. The entropic term in $\mathrm{CH}_{3} \mathrm{CN}$ solution $\left(\mathrm{S}_{\mathrm{s}}\right)$ was calculated according to the procedure described by Wertz [94] and Cooper and Ziegler [95] using Equations (5)-(6):

$$
\begin{gathered}
\Delta \mathrm{S}_{1}=\mathrm{R} \ln \left(\mathrm{V}_{\mathrm{m}, \mathrm{liq}}^{\mathrm{s}} / \mathrm{V}_{\mathrm{m}, \text { gas }}\right) \\
\Delta \mathrm{S}_{2}=\mathrm{R} \ln \left(\mathrm{V}_{\mathrm{m}}^{\circ} / \mathrm{V}_{\mathrm{m}, \mathrm{liq}}^{\mathrm{s}}\right) \\
\alpha=\left[\mathrm{S}^{\circ, \mathrm{s}}{ }_{\text {liq }}-\left(\mathrm{S}^{\circ, \mathrm{s}}{ }_{\text {gas }}+\Delta \mathrm{S}_{1}\right)\right] /\left[\mathrm{S}^{\circ, \mathrm{s}}{ }_{\text {gas }}+\Delta \mathrm{S}_{1}\right] \\
\mathrm{S}_{\mathrm{s}}=\mathrm{S}_{\mathrm{g}}+\Delta \mathrm{S}_{\mathrm{sol}}=\mathrm{S}_{\mathrm{g}}+\left[\Delta \mathrm{S}_{1}+\alpha\left(\mathrm{S}_{\mathrm{g}}+\Delta \mathrm{S}_{1}\right)+\Delta \mathrm{S}_{2}\right]= \\
\mathrm{S}_{\mathrm{g}}+\left[(-12.21 \mathrm{cal} / \mathrm{mol} \bullet \mathrm{K})-0.23\left(\mathrm{~S}_{\mathrm{g}}-12.21 \mathrm{cal} / \mathrm{mol} \bullet \mathrm{K}\right)+5.87 \mathrm{cal} / \mathrm{mol} \bullet \mathrm{K}\right]
\end{gathered}
$$

where $S_{g}$ is the gas-phase entropy of solute, $\Delta S_{\text {sol }}$ is the solvation entropy, $S^{o, s}{ }_{l i q}, S^{o, s}$ gas and $V_{m}^{s}$,liq are the standard entropies and molar volume of the solvent in the liquid or gas phases (149.62 and $245.48 \mathrm{~J} / \mathrm{mol} \bullet \mathrm{K}$ and $52.16 \mathrm{~mL} / \mathrm{mol}$, respectively, for $\mathrm{CH}_{3} \mathrm{CN}$ ), $\mathrm{V}_{\mathrm{m} \text {,gas }}$ is the molar volume of the ideal gas at $25{ }^{\circ} \mathrm{C}(24450 \mathrm{~mL} / \mathrm{mol}), \mathrm{V}^{\mathrm{o}} \mathrm{m}$ is the molar volume of the solution that correspond to the standard conditions $(1000 \mathrm{~mL} / \mathrm{mol})$. The enthalpies and Gibbs free energies in solution $\left(\mathrm{H}_{\mathrm{s}}\right.$ and $\mathrm{G}_{\mathrm{s}}$, respectively) were estimated using the expressions 9 and 10

$$
\begin{gathered}
\mathrm{H}_{\mathrm{s}}=\mathrm{E}_{\mathrm{s}}-\mathrm{E}_{\mathrm{g}}+\mathrm{H}_{\mathrm{g}} \\
\mathrm{G}_{\mathrm{s}}=\mathrm{H}_{\mathrm{s}}-\mathrm{TS}_{\mathrm{s}}
\end{gathered}
$$


where $E_{S}$ and $E_{g}$ are the total energies in solution and the gas phase and $H_{g}$ is the gas-phase enthalpy. Gibbs free energies in solution are discussed in this work if not stated otherwise.

\subsection{Materials}

All manipulations were carried out in air. Vanadium tribromide $\left(\mathrm{VBr}_{3}\right)$ was synthesized from elements as described in Reference [96]. The other reagent-grade chemicals were obtained from Aldrich and used without further purification. All solvents were distilled by standard methods before use.

\subsection{Physical Measurements}

An elemental analysis was performed on a Euro EA $3000 \mathrm{CHN}$ elemental analyzer. The IR spectra $\left(4000-400 \mathrm{~cm}^{-1}\right)$ were recorded on a Scimitar FTS 2000 Fourier-spectrometer.

\subsection{X-ray Crystallography}

The crystallographic data and refinement details for $\mathbf{3}$ and $\mathbf{4 a}$ are given in Table 1 . The diffraction data were collected on New Xcalibur (Agilent Technologies, Santa Clara, CA, United States) and Bruker Apex Duo diffractometers with MoK $\alpha$ radiation $(\lambda=0.71073)$. An absorption correction was done empirically using SCALE3 ABSPACK (CrysAlisPro, Agilent Technologies, Version 1.171.37.35 (release 13-08-2014 CrysAlis171 NET)) and SADABS (Bruker-AXS, 2004). The structures were solved by a dual algorithm [97] and refined by a full-matrix least-squares treatment against $|\mathrm{F}|^{2}$ in anisotropic approximation with SHELX 2017/1 [98] in the ShelXle program [99]. The hydrogen atoms were refined in geometrically calculated positions. The main geometrical parameters are summarized in Table 2. The crystallographic data have been deposed in the Cambridge Crystallographic Data Centre under the deposition codes CCDC 1879273 (3) and 1879274 (4a).

\section{Conclusions}

New polymeric oxidovanadium(IV) complexes, $\left[\mathrm{VO}(\mathrm{L}) \mathrm{X}_{2}\right]_{\mathrm{n}}(\mathrm{L}=$ bpy, phen and $\mathrm{X}=\mathrm{Cl}, \mathrm{Br})$, have been synthesized and structurally characterized. The experimental kinetic and selectivity data and DFT calculations indicated that the simple Fenton mechanism is operating for the oxidation of alkanes catalyzed by the $\mathrm{V}(\mathrm{IV})$ complexes under study. This mechanism includes (i) the formation of the monomeric active catalytic forms $\left[\mathrm{VO}(\mathrm{L}) \mathrm{X}_{2}(\mathrm{Solv})\right]\left(\mathrm{Solv}=\mathrm{H}_{2} \mathrm{O}, \mathrm{CH}_{3} \mathrm{CN}\right)$, (ii) the substitution of the coordinated solvent for the $\mathrm{H}_{2} \mathrm{O}_{2}$ molecule, (iii) the generation of the $\mathrm{HO}^{\bullet}$ radical upon the $\mathrm{HO}-\mathrm{OH}$ bond cleavage and (iv) the oxidation of the alkane molecules by $\mathrm{HO}^{\bullet}$ via hydrogen abstraction followed by the reaction with molecular oxygen to give alkyle hydroperoxides.

\section{Syntheses of the Complexes}

\subsection{Synthesis of $\left[V^{I V} \mathrm{O}(\text { bpy }) \mathrm{Cl}_{2}\right]_{n}(\mathbf{1})$}

A mixture of $\left[\mathrm{VCl}_{3}(\mathrm{thf})_{3}\right](100 \mathrm{mg}, 268 \mu \mathrm{mol}), 2,2^{\prime}$-bipyridine $(42 \mathrm{mg}, 268 \mu \mathrm{mol})$ and $\mathrm{CH}_{3} \mathrm{CN}$ $(5 \mathrm{~mL})$ was heated at $100^{\circ} \mathrm{C}$ in a sealed Teflon container for $30 \mathrm{~h}$. The slow cooling to room temperature gave needle-like crystals of $\mathbf{1}$ which were separated by filtration, washed with $\mathrm{CH}_{3} \mathrm{CN}$ and $\mathrm{Et}_{2} \mathrm{O}$ and dried in a vacuum. Yield: $71 \mathrm{mg}(90 \%)$. Anal. Calc. for $\mathrm{C}_{10} \mathrm{H}_{8} \mathrm{Cl}_{2} \mathrm{~N}_{2} \mathrm{OV}: \mathrm{C}, 40.8 \%$; N, 9.5\%; and $\mathrm{H}$, 2.7\%. Found: C, 40.5\%; N, 9.4\%; and H, 2.8\%. IR (KBr) v/ $\mathrm{cm}^{-1}$ : 3113(w), 3077(w), 3053(w), 3038(w), 2001(vw), 1971(vw), 1942(vw), 1898(vw), 1867(vw), 1670(vw), 1643(vw), 1605(s), 1567(w), 1498(w), 1474(m), 1446(s), 1321(m), 1246(w), 1169(m), 1117(w), 1076(w), 1059(w), 1043(w), 973(w), 1031(m), 889(vs), 766(s), 729(s), 663(w), 653(w), 644(w), 451(w) and 414(w).

\subsection{Synthesis of $\left[V^{I V} \mathrm{O} \text { (phen) } \mathrm{Cl}_{2}\right]_{n}$ (2)}

The synthesis of $\mathbf{2}$ was carried out under the same conditions as described for $\mathbf{1}$ using $\left[\mathrm{VCl}_{3}(\mathrm{thf})_{3}\right.$ ] (100 mg, $268 \mu \mathrm{mol}$ ) and 1,10-phenanthroline ( $48 \mathrm{mg}, 268 \mu \mathrm{mol})$. A green microcrystalline product was 
obtained. Yield: $57 \mathrm{mg}$ (65\%). Anal. Calc. for $\mathrm{C}_{12} \mathrm{H}_{8} \mathrm{Cl}_{2} \mathrm{~N}_{2} \mathrm{OV}$ : C, $45.3 \%$; N, 8.8\%; and $\mathrm{H}, 2.5 \%$. Found: C, 45.1\%; N, 9.0\%; and H, 2.7\%. IR (KBr) v/ $\mathrm{cm}^{-1}$ : 3080(w), 3053(br.w), 3010(w), 1629(w), 1607(w), 1584(m), 1521(s), 1495(w), 1428(vs), 1346(w), 1304(w), 1225(w), 1209(w), 1148(m), 1109(m), 891(bvs), 875(vs), 847(vs), 782(w), 739(m), 723(vs), 654(m), 559(w), 507(w) and 435(m).

\subsection{Synthesis of $\left[V^{I V} \mathrm{O}(\mathrm{bpy}) \mathrm{Br}_{2}\right]_{n}$ (3)}

A mixture of $\mathrm{VBr}_{3}(150 \mathrm{mg}, 516 \mu \mathrm{mol}), 2,2^{\prime}$-bipyridine $(81 \mathrm{mg}, 516 \mu \mathrm{mol})$ and $\mathrm{CH}_{3} \mathrm{CN}(10 \mathrm{~mL})$ was heated at $100{ }^{\circ} \mathrm{C}$ in a sealed Teflon container for $12 \mathrm{~h}$. The slow cooling to room temperature gave a mixture of green crystals (major) and an orange powder (minor). The mixture was washed with $\mathrm{CH}_{3} \mathrm{CN}$ and $\mathrm{Et}_{2} \mathrm{O}$ and dried in a vacuum. The green crystals were mechanically separated from the orange powder. Yield: $124 \mathrm{mg}(66 \%)$ Anal. Calc. for $\mathrm{C}_{10} \mathrm{H}_{8} \mathrm{Br}_{2} \mathrm{~N}_{2} \mathrm{OV}$ : C, 31.4\%; N, 7.3\%; and $\mathrm{H}, 2.1 \%$. Found: C, 31.1\%; N, 7.1\%; and H, 2.3\%. IR (KBr) v/ $\mathrm{cm}^{-1}$ : 3112(w), 3093(w), 3074(w), 3059(w), 3035(w), 2917(w), 2850(w), 1601(s), 1566(w), 1494(w), 1471(m), 1440(s), 1319(m), 1310(m), 1243(w), 1216(w), 1167(m), 1114(w), 1102(w), 1061(w), 1044(w), 1029(s), 1021(m), 875(vs), 769(s), 727(s), 661(m), 650(w), 643(w), 447(w) and 413(w).

\subsection{Synthesis of $\left[V^{I V} \mathrm{O}(\mathrm{phen}) \mathrm{Br}_{2}\right]_{n}$ (4)}

The synthesis of 4 was carried out under the same conditions as described for 3 using $\mathrm{VBr}_{3}$ $(150 \mathrm{mg}, 516 \mu \mathrm{mol})$ and 1,10-phenanthroline $(93 \mathrm{mg}, 516 \mu \mathrm{mol})$. A green microcrystalline product was obtained. Yield: $124 \mathrm{mg}$ (43\%). Anal. Calc. for $\mathrm{C}_{12} \mathrm{H}_{8} \mathrm{Br}_{2} \mathrm{~N}_{2} \mathrm{OV}$ : C, 35.4\%; N, 6.9\%; and $\mathrm{H}, 2.0 \%$. Found: C, 34.9\%; N, 7.0\%; and H, 2.3\%. IR (KBr) v/ $\mathrm{cm}^{-1}$ : 3078(w), 3051(w), 3011(w), 1734(w), 1629(m), 1607(m), 1584(m), 1521(m), 1495(w), 1466(w), 1428(s), 1345(w), 1304(w), 1225(w), 1210(w), 1149(m), 1109(m), 978(w), 882(vs), 846(m), 779(w), 739(m), 721(s), 654(w), 509(w) and 434(m).

\subsection{Oxidation of Alcohols and Hydrocarbons with Peroxides}

The reactions of alcohols and hydrocarbons were usually carried out in air in thermostated Pyrex cylindrical vessels with vigorous stirring, using $\mathrm{MeCN}$ as the solvent. Typically, the catalyst (1-4) and the cocatalyst (acid) were introduced into the reaction mixture in the form of stock solutions in acetonitrile. The substrate (alcohol or hydrocarbon) was then added, and the reaction started when hydrogen peroxide or TBHP was introduced in one portion. (CAUTION: The combination of air or molecular oxygen and $\mathrm{H}_{2} \mathrm{O}_{2}$ with organic compounds at elevated temperatures may be explosive). The reactions with benzene and 1-phenyethanol were analyzed by the ${ }^{1} \mathrm{H}$ NMR method (solutions in acetone- $d_{6}$; "Bruker AMX-400" instrument, $400 \mathrm{MHz}$ ). For the determination of the concentrations of phenol and $p$-quinone, the signals in the aromatic region were integrated using added 1,4-dinitrobenzene as a standard. The areas of methyl group signals were measured to quantify the oxygenates formed in the oxidations of 1-phenylethanol.

In order to determine the concentrations of all the cyclohexane oxidation products, the samples of the reaction solutions after the addition of nitromethane as a standard compound were, in some cases, analyzed twice (before and after their treatment with $\mathrm{PPh}_{3}$ ) by GC (chromatograph-3700, fused silica capillary column FFAP/OV-101 20/80 w/w, 30 m $\times 0.2 \mathrm{~mm} \times 0.3 \mu \mathrm{m}$; helium as a carrier gas) to measure the concentrations of cyclohexanol and cyclohexanone. This method (an excess of solid triphenylphosphine was added to the samples 10-15 min before the GC analysis) was proposed by one of us (Shul'pin, G.B.) earlier [4,5,46,47,68-82]. The attribution of peaks was made by a comparison with the chromatograms of authentic samples. Blank experiments with cyclohexane showed that, in the absence of the catalyst, no products were formed.

Supplementary Materials: The following are available online at http:/ /www.mdpi.com/2073-4344/9/3/217/s1.

Author Contributions: A.L.G. and G.B.S. conceived and designed the experiments; I.S.F., P.A.A., N.S.I. and L.S.S. performed the experiments; M.L.K., Y.N.K., M.N.S., A.J.L.P. and G.B.S. analyzed the data; M.L.K. performed the DFT calculations and wrote the theoretical part; A.L.G. and G.B.S. wrote the paper. 
Funding: This work has been supported by the Russian Foundation for Basic Research (Grants No. 19-03-142 and 18-03-00155) and the RUDN University Program "5-100" as well as by the Initiative Programs (State registration number AAAA-A16-116020350251-6) in the frames of the State Task 0082-2014-0007, "Fundamental regularities of heterogeneous and homogeneous catalysis" and number AAAA-A17-117040610283-3 within the framework of the Programs of Fundamental Research of the Russian Academy of Sciences for 2013-2020 on the research issue of IChP RAS (Theme number in the Federal Agency for Scientific Organizations: 0082-2014-0004) and on the research issue of IPCP RAS (Theme number in the Federal Agency for Scientific Organizations: 0089-2014-0032). This work has been partially supported by the Fundação para a Ciência e a Tecnologia (FCT), Portugal (projects UID/QUI/00100/2013 and PTDC/QEQ-QIN/3967/2014).

Conflicts of Interest: The authors declare no conflict of interest.

\section{References}

1. Shilov, A.E.; Shul'pin, G.B. Activation of C-H Bonds by Metal Complexes. Chem. Rev. 1997, 97, $2879-2932$. [CrossRef] [PubMed]

2. Shilov, A.E.; Shul'pin, G.B. Activation and Catalytic Reactions of Saturated Hydrocarbons in the Presence of Metal Complexes; Kluwer Academic Publishers: New York, NY, USA; Boston, MA, USA; Dordrecht, The Netherlands; London, UK; Moscow, Russia, 2002.

3. Shul'pin, G.B. Oxidations of C-H Compounds Catalyzed by Metal Complexes. In Transition Metals for Organic Synthesis, 2nd ed.; Beller, M., Bolm, C., Eds.; Wiley-VCH: Weinheim, Germany; New York, NY, USA, 2004; Volume 2, pp. 215-242.

4. Shul'pin, G.B. Metal-catalysed hydrocarbon oxidations. Mini-Rev. Org. Chem. 2009, 6, 95-104. [CrossRef]

5. Shul'pin, G.B. Selectivity enhancement in functionalization of $\mathrm{C}-\mathrm{H}$ bonds: A review. Org. Biomol. Chem. 2010, 8, 4217-4228. [CrossRef] [PubMed]

6. Shul'pin, G.B. Selectivity in C-H functionalizations. In Comprehensive Inorganic Chemistry II, 2nd ed.; Reedijk, J., Poeppelmeier, K., Casella, L., Eds.; Elsevier: Amsterdam, The Netherlands, 2013; Volume 6, Chapter 6.04; pp. 79-104.

7. Wójtowicz-Młochowska, H. Synthetic utility of metal catalyzed hydrogen peroxide oxidation of C-H, C-C and $\mathrm{C}=\mathrm{C}$ bonds in alkanes, arenes and alkenes: Recent advances. Arkivoc 2017, ii, 12-58.

8. Shul'pin, G.B. Radical versus non-radical mechanisms. In Alkane Functionalization; Pombeiro, A.J.L., Ed.; Wiley, Inc.: Hoboken, NJ, USA, 2018; Chapter 3.

9. Milan, M.; Salamone, M.; Costas, M.; Bietti, M. The Quest for Selectivity in Hydrogen Atom Transfer Based Aliphatic C-H Bond Oxygenation. Acc. Chem. Res. 2018, 51, 1984-1995. [CrossRef] [PubMed]

10. Poon, J.-F.; Pratt, D.A. Recent Insights on Hydrogen Atom Transfer in the Inhibition of Hydrocarbon Autoxidation. Acc. Chem. Res. 2018, 51, 1996-2005. [CrossRef] [PubMed]

11. Kaim, W. Manifestations of Noninnocent Ligand Behavior. Inorg. Chem. 2011, 50, 9752-9765. [CrossRef] [PubMed]

12. Kaim, W. The transition metal coordination chemistry of anion radicals. Coord. Chem. Rev. 1987, 76, 187-235. [CrossRef]

13. Lyaskovskyy, V.; Bruin, B.D. Redox Non-Innocent Ligands: Versatile New Tools to Control Catalytic Reactions. ACS Catal. 2012, 2, 270-279. [CrossRef]

14. Chirik, P.J.; Wieghardt, K. Radical Ligands Confer Nobility on Base-Metal Catalysts. Science 2010, 327, 794-795. [CrossRef] [PubMed]

15. Heyduk, A.F.; Zarkesh, R.A.; Nguyen, A.I. Designing catalysts for nitrene transfer using early transition metals and redox-active ligands. Inorg. Chem. 2011, 50, 9849-9863. [CrossRef] [PubMed]

16. Praneeth, V.K.K.; Ringenberg, M.R.; Ward, T.R. Redox-Active Ligands in Catalysis. Angew. Chem. Int. Ed. 2012, 51, 10228-10234. [CrossRef] [PubMed]

17. Wright, D.D.; Brown, S.N. Nonclassical oxygen atom transfer as a synthetic strategy: Preparation of an oxorhenium(V) complex of the bis(3,5-di-tert-butyl-2-phenoxo)amide ligand. Inorg. Chem. 2013, 52, 7831-7833. [CrossRef] [PubMed]

18. Sutradhar, M.; Martins, L.M.D.R.S.; Guedes da Silva, M.F.C.; Pombeiro, A.J.L. Vanadium complexes: Recent progress in oxidation catalysis. Coord. Chem. Rev. 2015, 301, 200-239. [CrossRef]

19. Pessoa, J.C.; Maurya, M.R. Vanadium complexes supported on organic polymers as sustainable systems for catalytic oxidations. Inorg. Chim. Acta 2017, 455, 415-428. [CrossRef] 
20. Shul'pin, G.B. Organometallic Complexes as Catalysts in Oxidation of C-H Compounds. In Advances in Organometallic Chemistry and Catalysis; Pombeiro, A.J.L., Ed.; Wiley: Hoboken, NJ, USA, 2014; Chapter 1; pp. 3-14.

21. Mandelli, D.; Shul'pina, L.S.; Kirillova, M.V.; Kirillov, A.M.; Carvalho, W.A.; Pombeiro, A.J.L.; Shul'pin, G.B. Oxidation of Glycerol with Hydrogen Peroxide catalyzed by Metal Complexes. In Advances in Organometallic Chemistry and Catalysis; Pombeiro, A.J.L., Ed.; Wiley: Hoboken, NJ, USA, 2014; Chapter 19; pp. 247-258.

22. Shul'pin, G.B. Alkane-oxidizing systems based on metal complexes. Radical versus non-radical mechanisms. In Alkane Functionalization; Pombeiro, A.J.L., Ed.; Wiley: Hoboken, NJ, USA, 2018; Chapter 2.

23. Butler, A. Mechanistic considerations of the vanadium haloperoxidases. Coord. Chem. Rev. 1999, 187, 17-35. [CrossRef]

24. Wischang, D.; Brücher, O.; Hartung, J. Bromoperoxidases and functional enzyme mimics as catalysts for oxidative bromination-A sustainable synthetic approach. Coord. Chem. Rev. 2011, 255, 2204-2217.

25. Fomenko, Y.S.; Gushchin, A.L.; Tkachev, A.V.; Vasilyev, E.S.; Abramov, P.A.; Nadolinny, V.A.; Syrokvashin, M.M.; Sokolov, M.N. First oxidovanadium complexes containing chiral derivatives of dihydrophenanthroline and diazafluorene. Polyhedron 2017, 135, 96-100. [CrossRef]

26. King, A.E.; Nippe, M.; Atanasov, M.; Chantarojsiri, T.; Wray, C.A.; Bill, E.; Neese, F.; Long, J.R.; Chang, C.J. A Well-Defined Terminal Vanadium(III) Oxo Complex. Inorg. Chem. 2014, 53, 11388-11395. [CrossRef] [PubMed]

27. Smith, K.I.; Borer, L.L.; Olmstead, M.M. Vanadium(IV) and vanadium(V) complexes of salicyladimine ligands. Inorg. Chem. 2003, 42, 7410-7415. [CrossRef] [PubMed]

28. Hanson, S.K.; Baker, R.T.; Gordon, J.C.; Scott, B.L.; Silks, L.A.P.; Thorn, D.L. Mechanism of Alcohol Oxidation by Dipicolinate Vanadium(V): Unexpected Role of Pyridine. J. Am. Chem. Soc. 2010, 132, 17804-17816. [CrossRef] [PubMed]

29. Hanson, S.K.; Wu, R.; Silks, L.A.P. Mild and Selective Vanadium-Catalyzed Oxidation of Benzylic, Allylic, and Propargylic Alcohols Using Air. Org. Lett. 2011, 13, 1908-1911. [CrossRef] [PubMed]

30. Hanson, S.K.; Wu, R.; Silks, L.A.P. C-C or C-O Bond Cleavage in a Phenolic Lignin Model xtc60 Compound: Selectivity Depends on Vanadium Catalyst. Angew. Chem. Int. Ed. 2012, 124, 3466-3469. [CrossRef]

31. Zhang, G.; Scott, B.L.; Wu, R.; Silks, L.A.P.; Hanson, S.K. Aerobic Oxidation Reactions Catalyzed by Vanadium Complexes of Bis(Phenolate) Ligands. Inorg. Chem. 2012, 51, 7354-7361. [CrossRef] [PubMed]

32. Hanson, S.K.; Baker, R.T.; Gordon, J.C.; Scott, B.L.; Thorn, D.L. Aerobic oxidation of lignin models using a base metal vanadium catalyst. Inorg. Chem. 2010, 49, 5611-5618. [CrossRef] [PubMed]

33. Tsuchida, E.; Oyaizu, K. Oxovanadium (III-V) mononuclear complexes and their linear assemblies bearing tetradentate Schiff base ligands: Structure and reactivity as multielectron redox catalysts. Coord. Chem. Rev. 2003, 237, 213-228. [CrossRef]

34. Chang, C.J.; Labinger, J.A.; Gray, H.B. Aerobic epoxidation of olefins catalyzed by electronegative vanadyl salen complexes. Inorg. Chem. 1997, 36, 5927-5930. [CrossRef] [PubMed]

35. Hamilton, D.E. Reinvestigation of the vanadium-oxygen stretch in the IR spectrum of bis [N-(4-chlorophenyl)salicylideneiminato] oxovanadium (IV). Inorg. Chem. 1991, 30, 1670-1671. [CrossRef]

36. Matsuoka, N.; Kawamura, H.; Yoshioka, N. Magnetic property and crystal structure of bis [N-(4-chlorophenyl)salicylideneaminato] oxovanadium (IV). Chem. Phys. Lett. 2010, 488, 32-37. [CrossRef]

37. Nakajima, K.; Kojima, M.; Azuma, S.; Kasahara, R.; Tsuchimoto, M.; Kubozono, Y.; Maeda, H.; Kashino, S.; Ohba, S.; Yoshikawa, Y.; et al. Interconversion between polymeric orange and monomeric green forms of a Schiff base-oxovanadium (IV) complex. Bull. Chem. Soc. Jpn. 1996, 69, 3207-3216. [CrossRef]

38. Fairhurst, S.A.; Hughes, D.L.; Kleinkes, U.; Leigh, J.G.; Sanders, J.R.; Weisner, J. Non-planar co-ordination of the Schiff-base dianion N, $\mathrm{N}^{\prime}$-2, 2-dimethyltrimethylenebis [salicylideneiminate(2-)] to vanadium. J. Chem. Soc. Dalton Trans. 1995, 3, 321-326. [CrossRef]

39. Tsuchimoto, M.; Hoshina, G.; Yoshioka, N.; Inoue, H.; Nakajima, K.; Kamishima, M.; Kojima, M.; Ohba, S. Mechanochemical reaction of polymeric oxovanadium (IV) complexes with Schiff base ligands derived from 5-nitrosalicylaldehyde and diamines. J. Solid State Chem. 2000, 153, 9-15. [CrossRef]

40. Shul'pin, G.B.; Attanasio, D.; Suber, L. Efficient $\mathrm{H}_{2} \mathrm{O}_{2}$ oxidation of alkanes and arenes to alkyl peroxides and phenols catalyzed by the system vanadate-pyrazine-2-carboxylic acid. J. Catal. 1993, 142, 147-152. [CrossRef]

41. Shul'pin, G.B.; Attanasio, D.; Suber, L. Oxidations by a $\mathrm{H}_{2} \mathrm{O}_{2}-\mathrm{VO}_{3}{ }^{-}$-pyrazine-2-carboxylic acid reagent. 1. Oxidations of alkanes in $\mathrm{CH}_{3} \mathrm{CN}$ to produce alkyl peroxides. Russ. Chem. Bull. 1993, 42, 55-59. [CrossRef] 
42. Shul'pin, G.B.; Druzhinina, A.N.; Nizova, G.V. Oxidation with the $\mathrm{H}_{2} \mathrm{O}_{2}-\mathrm{VO}_{3}{ }^{-}$-pyrazine-2-carboxylic acid reagent. 2. Oxidation of alcohols and aromatic hydrocarbons. Russ. Chem. Bull. 1993, 42, 1327-1329.

43. Nizova, G.V.; Shul'pin, G.B. Oxidation by a $\mathrm{H}_{2} \mathrm{O}_{2}$-vanadium complex-2-pyrazinecarboxylic acid reagent. 3. Evidence for hydroxyl radical formation. Russ. Chem. Bull. 1994, 43, 1146-1148. [CrossRef]

44. Shul'pin, G.B.; Süss-Fink, G. Oxidations by the reagent " $\mathrm{H}_{2} \mathrm{O}_{2}$-vanadium complex-pyrazine-2-carboxylic acid." Part 4. Oxidation of alkanes, benzene and alcohols by an adduct of $\mathrm{H}_{2} \mathrm{O}_{2}$ with urea. J. Chem. Soc. Perkin Trans. 1995, 2, 1459-1463. [CrossRef]

45. Shul'pin, G.B.; Drago, R.S.; Gonzalez, M. Oxidations by a “ $\mathrm{H}_{2} \mathrm{O}_{2}$-vanadium complex-pyrazine-2-carboxylic acid" reagent. 5. Oxidation of lower alkanes with the formation of carbonyl compounds. Russ. Chem. Bull. 1996, 45, 2386-2388. [CrossRef]

46. Shul'pin, G.B.; Guerreiro, M.C.; Schuchardt, U. Oxidations by the reagent $\mathrm{O}_{2}-\mathrm{H}_{2} \mathrm{O}_{2}$-vanadium complexpyrazine-2-carboxylic acid. Part 7. Hydroperoxidation of higher alkanes. Tetrahedron 1996, 52, 13051-13062. [CrossRef]

47. Guerreiro, M.C.; Schuchardt, U.; Shul'pin, G.B. Oxidation with the " $\mathrm{O}_{2}-\mathrm{VO}_{3}{ }^{-}$-pyrazine-2-carboxylic acid" reagent. Part 6. Oxidation of $n$-heptane and cyclohexane. Direct determination of alkyl hydroperoxides by gas-liquid chromatography. Russ. Chem. Bull. 1997, 46, 749-754. [CrossRef]

48. Nizova, G.V.; Süss-Fink, G.; Shul'pin, G.B. Oxidations by the reagent $« \mathrm{O}_{2}-\mathrm{H}_{2} \mathrm{O}_{2}$-vanadium complexpyrazine-2-carboxylic acid»-8. Efficient oxygenation of methane and other lower alkanes in acetonitrile. Tetrahedron 1997, 53, 3603-3614. [CrossRef]

49. Schuchardt, U.; Guerreiro, M.C.; Shul'pin, G.B. Oxidation with the ' $\mathrm{O}_{2}-\mathrm{H}_{2} \mathrm{O}_{2}$-vanadium complex-pyrazine -2-carboxylic acid' reagent. 9. Oxidation of cyclohexene and decalin. Russ. Chem. Bull. 1998, 47, 247-252. [CrossRef]

50. Süss-Fink, G.; Nizova, G.V.; Stanislas, S.; Shul'pin, G.B. Oxidations by the reagent ' $\mathrm{O}_{2}-\mathrm{H}_{2} \mathrm{O}_{2}-$ vanadate anion-pyrazine-2-carboxylic acid'. Part 10. Oxygenation of methane in acetonitrile and water. J. Mol. Catal. A Chem. 1998, 130, 163-170. [CrossRef]

51. Shul'pin, G.B.; Ishii, Y.; Sakaguchi, S.; Iwahama, T. Oxidations with the " $\mathrm{O}_{2}-\mathrm{H}_{2} \mathrm{O}_{2}$-vanadium complex-pyrazine-2-carboxylic acid" reagent. 11. Oxidation of styrene, phenylacetylene, and their derivatives with the formation of benzaldehyde and benzoic acid. Russ. Chem. Bull. 1999, 48, 887-890. [CrossRef]

52. Süss-Fink, G.; Stanislas, S.; Shul'pin, G.B.; Nizova, G.V.; Stoeckli-Evans, H.; Neels, A.; Bobillier, C.; Claude, S. Oxidative functionalisation of alkanes: Synthesis, molecular structure and catalytic implications of anionic vanadium(V) oxo and peroxo complexes containing bidentate N,O ligands. J. Chem. Soc. Dalton Trans. 1999, 18, 3169-3175. [CrossRef]

53. Shul'pin, G.B.; Kozlov, Y.N.; Nizova, G.V.; Süss-Fink, G.; Stanislas, S.; Kitaygorodskiy, A.; Kulikova, V.S. Oxidations by the reagent " $\mathrm{O}_{2}-\mathrm{H}_{2} \mathrm{O}_{2}$-vanadium derivative-pyrazine-2-carboxylic acid" Part 12. Main features, kinetics and mechanism of alkane hydroperoxidation. J. Chem. Soc. Perkin Trans. 2 2001, 8, 1351-1371. [CrossRef]

54. De la Cruz, M.H.C.; Kozlov, Y.N.; Lachter, E.R.; Shul'pin, G.B. Oxidations by the reagent " $\mathrm{O}_{2}-\mathrm{H}_{2} \mathrm{O}_{2}$-vanadium derivative-Pyrazine-2-carboxylic acid". Part 13. Kinetics and mechanism of the benzene hydroxylation. New J. Chem. 2003, 27, 634-638. [CrossRef]

55. Shul'pin, G.B.; Kozlov, Y.N. Kinetics and mechanism of alkane hydroperoxidation with tert-butyl hydroperoxide catalysed by a vanadate ion. Org. Biomol. Chem. 2003, 1, 2303-2306. [CrossRef] [PubMed]

56. Cuervo, L.G.; Kozlov, Y.N.; Süss-Fink, G.; Shul'pin, G.B. Oxidation of saturated hydrocarbons with peroxyacetic acid catalyzed by vanadium complexes. J. Mol. Catal. A Chem. 2004, 218, 171-177. [CrossRef]

57. Kozlov, Y.N.; Nizova, G.V.; Shul'pin, G.B. Oxidations by the reagent “ $\mathrm{O}_{2}-\mathrm{H}_{2} \mathrm{O}_{2}$-vanadium derivative-pyrazine-2-carboxylic acid". Part 14. Competitive oxidation of alkanes and acetonitrile (solvent). J. Mol. Catal. A Chem 2005, 227, 247-253. [CrossRef]

58. Jannini, M.J.D.M.; Shul'pina, L.S.; Schuchardt, U.; Shul'pin, G.B. Oxidation of alkanes with hydrogen peroxide catalyzed by the "vanadate-ion-pyrazine-2-carboxylic acid" system in the presence of pyridine (Part 15 of the series Oxidations by the reagent $\mathrm{O}_{2}-\mathrm{H}_{2} \mathrm{O}_{2}$-vanadium derivative-pyrazine-2-carboxylic acid). Petrol. Chem. 2005, 45, 413-418.

59. Kozlov, Y.N.; Romakh, V.B.; Kitaygorodskiy, A.; Buglyó, P.; Süss-Fink, G.; Shul'pin, G.B. Oxidation of 2-Propanol and Cyclohexane by the Reagent "Hydrogen Peroxide-Vanadate Anion-Pyrazine-2-carboxylic Acid": Kinetics and Mechanism. J. Phys. Chem. A 2007, 111, 7736-7752. [CrossRef] [PubMed] 
60. Kirillova, M.V.; Kuznetsov, M.L.; Romakh, V.B.; Shul'pina, L.S.; Fraústo da Silva, J.J.R.; Pombeiro, A.J.L.; Shul'pin, G.B. Mechanism of oxidations with $\mathrm{H}_{2} \mathrm{O}_{2}$ catalyzed by vanadate anion or oxovanadium(V) triethanolaminate (vanadatrane) in combination with pyrazine-2-carboxylic acid (PCA): Kinetic and DFT studies. J. Catal. 2009, 267, 140-157. [CrossRef]

61. Gusevskaya, E.V.; Menini, L.; Parreira, L.A.; Mesquita, R.A.; Kozlov, Y.N.; Shul'pin, G.B. Oxidation of isoeugenol to vanillin by the " $\mathrm{H}_{2} \mathrm{O}_{2}$-vanadate-pyrazine-2-carboxylic acid" reagent" $<$ Part 17 of the series "Oxidations by the reagent 'H2O2-vanadium derivative-pyrazine-2-carboxylic acid">. J. Mol. Catal. A Chem. 2012, 363-364, 140-147. [CrossRef]

62. Sutradhar, M.; Shvydkiy, N.V.; da Silva, M.F.C.G.; Kirillova, M.V.; Kozlov, Y.N.; Pombeiro, A.J.L.; Shul'pin, G.B. New binuclear oxovanadium(V) complex as a catalyst in combination with pyrazinecarboxylic acid (PCA) for efficient alkane oxygenation by $\mathrm{H}_{2} \mathrm{O}_{2}$. Dalton Trans. 2013, 42, 11791-11803. [CrossRef] [PubMed]

63. Fomenko, I.S.; Gushchin, A.L.; Shul'pina, L.S.; Ikonnikov, N.S.; Abramov, P.A.; Romashev, N.F.; Poryvaev, A.S.; Sheveleva, A.M.; Bogomyakov, A.S.; Shmelev, N.Y.; et al. New oxidovanadium (IV) complex with a BIAN ligand: Synthesis, structure, redox properties and catalytic activity. New J. Chem. 2018, 42, 16200-16210. [CrossRef]

64. Triantafillou, G.D.; Tolis, E.I.; Terzis, A.; Deligiannakis, Y.; Raptopoulou, C.P.; Sigalas, M.P.; Kabanos, T.A. Monomeric Oxovanadium (IV) Compounds of the General Formula cis- $\left[\mathrm{V}^{\mathrm{IV}}(=\mathrm{O})(\mathrm{X})\left(\mathrm{L}_{\mathrm{NN}}\right)_{2}\right]^{+/ 0}\left\{\mathrm{X}=\mathrm{OH}^{-}, \mathrm{Cl}^{-}, \mathrm{SO}_{4}{ }^{2-}\right.$ and $\mathrm{L}_{\mathrm{NN}}=2$, 2'-Bipyridine (Bipy) or 4, 4 '-Disubstituted Bipy\}. Inorg. Chem. 2004, 43, 79-91. [CrossRef] [PubMed]

65. Menati, S.; Rudbari, H.A.; Khorshidifard, M.; Jalilian, F. A new oxovanadium (IV) complex containing an O, N-bidentate Schiff base ligand: Synthesis at ambient temperature, characterization, crystal structure and catalytic performance in selective oxidation of sulfides to sulfones using $\mathrm{H}_{2} \mathrm{O}_{2}$ under solvent-free conditions. J. Mol. Struct. 2016, 1103, 94-102.

66. Das, U.; Pattanayak, P.; Santra, M.K.; Chattopadhyay, S. Synthesis of new oxido-vanadium complexes: Catalytic properties and cytotoxicity. J. Chem. Res. 2018, 42, 57-62. [CrossRef]

67. Kasahara, R.; Tsuchimoto, M.; Ohba, S.; Nakajima, K.; Ishida, H.; Kojima, M. Interconversion between polymeric and monomeric forms of oxovanadium (IV) complexes with tetradentate Schiff base ligands derived from (R, R)-2, 4-pentanediamine. Inorg. Chem. 1996, 35, 7661-7665. [CrossRef]

68. Shul'pin, G.B.; Druzhinina, A.N. Hydroperoxidation of alkanes by atmospheric oxygen in the presence of hydroquinone or quinone catalyzed by copper(II) acetate under visible light irradiation. React. Kinet. Catal. Lett. 1992, 47, 207-211. [CrossRef]

69. Shul'pin, G.B.; Nizova, G.V. Formation of alkyl peroxides in oxidation of alkanes by $\mathrm{H}_{2} \mathrm{O}_{2}$ catalyzed by transition metal complexes. React. Kinet. Catal. Lett. 1992, 48, 333-338. [CrossRef]

70. Shul'pin, G.B. Metal-catalysed hydrocarbon oxygenations in solutions: The dramatic role of additives: A review . J. Mol. Catal. A Chem. 2002, 189, 39-66. [CrossRef]

71. Shul'pin, G.B. Metal-catalysed hydrocarbon oxidations. C. R. Chim. 2003, 6, 163-178. [CrossRef]

72. Shul'pin, G.B.; Kozlov, Y.N.; Shul'pina, L.S.; Kudinov, A.R.; Mandelli, D. Extremely Efficient Alkane Oxidation by a New Catalytic Reagent $\mathrm{H}_{2} \mathrm{O}_{2} / \mathrm{Os}_{3}(\mathrm{CO})_{12}$ /Pyridine. Inorg. Chem. 2009, 48, 10480-10482. [CrossRef] [PubMed]

73. Shul'pin, G.B.; Kozlov, Y.N.; Shul'pina, L.S.; Petrovskiy, P.V. Oxidation of alkanes and alcohols with hydrogen peroxide catalyzed by complex $\mathrm{Os}_{3}(\mathrm{CO})_{10}(-\mathrm{H})_{2}$. Appl. Organometal. Chem. 2010, 24, 464-472. [CrossRef]

74. Knops-Gerrits, P.P.; Trujillo, C.A.; Zhan, B.Z.; Li, X.Y.; Rouxhet, P.; Jacobs, P.A. Oxidation catalysis with well-characterised vanadyl bis-bipyridine complexes encapsulated in NaY zeolite. Top. Catal. 1996, 3, 437-449. [CrossRef]

75. Fornal, E.; Giannotti, C. Photocatalyzed oxidation of cyclohexane with heterogenized decatungstate. Photochem. Photobiol. A Chem. 2007, 188, 279-286. [CrossRef]

76. Shul'pin, G.B. Hydrocarbon Oxygenations with Peroxides Catalyzed by Metal Compounds. Mini-Rev. Org. Chem. 2009, 6, 95-104. [CrossRef]

77. Shul'pin, G.B. Metal-catalyzed oxidation of C-H compounds with peroxides in unconventional solvents. Frontiers of Green Catalytic Selective Oxidations. Nat. Chem. 2019. Chapter 1.

78. Shul'pin, G.B. C-H Functionalization: Thoroughly tuning ligands at a metal ion, a chemist can greatly enhance catalyst's activity and selectivity. Dalton Trans. 2013, 42, 12794-12818. [CrossRef] [PubMed]

79. Shul'pin, G.B. New Trends in Oxidative Functionalization of Carbon-Hydrogen Bonds: A Review. Catalysts 2016, 6, 50. [CrossRef] 
80. Olivo, G.; Lanzalunga, O.; Di Stefano, S. Non-Heme Imine-Based Iron Complexes as Catalysts for Oxidative Processes (Review). Adv. Synth. Catal. 2016, 358, 843-863. [CrossRef]

81. Garcia-Bosch, I.; Siegel, M.A. Copper-Catalyzed Oxidation of Alkanes with $\mathrm{H}_{2} \mathrm{O}_{2}$ under a Fenton-like Regime. Angew. Chem. Int. Ed. 2016, 55, 12873-12876. [CrossRef] [PubMed]

82. Maksimov, A.L.; Kardasheva, Y.S.; Predeina, V.V.; Kluev, M.V.; Ramazanov, D.N.; Talanova, M.Y.; Karakhanov, E.A. Iron and copper complexes with nitrogen-containing ligands as catalysts for cyclohexane oxidation with hydrogen peroxide under mild reaction conditions. Petroleum Chem. 2012, 52, 318-326. [CrossRef]

83. Nesterov, D.S.; Chygorin, E.N.; Kokozay, V.N.; Bon, V.V.; Boča, R.; Kozlov, Y.N.; Shul'pina, L.S.; Jezierska, J.; Ozarowski, A.; Pombeiro, A.J.L.; et al. Heterometallic $\mathrm{Co}_{4}{ }_{4} \mathrm{Fe}{ }^{\mathrm{II}}{ }_{2}$ Schiff Base Complex: Structure, Electron Paramagnetic Resonance, and Alkane Oxidation Catalytic Activity. Inorg. Chem. 2012, 51, 9110-9122. [CrossRef] [PubMed]

84. Shul'pin, G.B.; Nesterov, D.S.; Shul'pina, L.S.; Pombeiro, A.J.L. A hydroperoxo-rebound mechanism of alkane oxidation with hydrogen peroxide catalyzed by binuclear manganese(IV) complex in the presence of an acid with involvement of atmospheric dioxygen" $<$ Part 14 from the series "Oxidations by the system "hydrogen peroxide- $\left[\mathrm{Mn}_{2} \mathrm{~L}_{2} \mathrm{O}_{3}\right]^{2+}$ (L=1,4,7-trimethyl-1,4,7-triazacyclononane)-carboxylic acid">. Inorg. Chim. Acta 2017, 455, 666-676.

85. Zhao, Y.; Truhlar, D.G. The M06 suite of density functionals for main group thermochemistry, thermochemical kinetics, noncovalent interactions, excited states, and transition elements: Two new functionals and systematic testing of four M06-class functionals and 12 other functionals. Theor. Chem. Acc. 2008, 120, 215-241.

86. Frisch, M.J.; Trucks, G.W.; Schlegel, H.B.; Scuseria, G.E.; Robb, M.A.; Cheeseman, J.R.; Scalmani, G.; Barone, V.; Mennucci, B.; Petersson, G.A.; et al. Gaussian 09, Revision A.01; Gaussian, Inc.: Wallingford, CT, USA, 2009.

87. Dolg, M.; Wedig, U.; Stoll, H.; Preuss, H. Energy-adjusted ab initio pseudopotentials for the first row transition elements. J. Chem. Phys. 1987, 86, 866-872. [CrossRef]

88. Gryca, I.; CzerwiĚska, K.; Machura, B.; Chrobok, A.; Shul'pina, L.S.; Kuznetsov, M.L.; Nesterov, D.S.; Kozlov, Y.N.; Pombeiro, A.J.L.; Varyan, I.A.; et al. High Catalytic Activity of Vanadium Complexes in Alkane Oxidations with Hydrogen Peroxide: An Effect of 8-Hydroxyquinoline Derivatives as Noninnocent Ligands. Inorg. Chem. 2018, 57, 1824-1839. [CrossRef] [PubMed]

89. Gonzalez, C.; Schlegel, H.B. Improved algorithms for reaction path following: Higher-order implicit algorithms. J. Chem. Phys. 1991, 95, 5853-5860. [CrossRef]

90. Gonzalez, C.; Schlegel, H.B. An improved algorithm for reaction path following. J. Chem. Phys. 1989, 90, $2154-2161$. [CrossRef]

91. Gonzalez, C.; Schlegel, H.B. Reaction path following in mass-weighted internal coordinates. J. Phys. Chem. 1990, 94, 5523-5527. [CrossRef]

92. Tomasi, J.; Persico, M. Molecular interactions in solution: An overview of methods based on continuous distributions of the solvent. Chem. Rev. 1994, 94, 2027-2094. [CrossRef]

93. Barone, V.; Cossi, M. Quantum calculation of molecular energies and energy gradients in solution by a conductor solvent model. J. Phys. Chem. A 1998, 102, 1995-2001. [CrossRef]

94. Wertz, G.H. Relationship between the gas-phase entropies of molecules and their entropies of solvation in water and 1-octanol. J. Am. Chem. Soc. 1980, 102, 5316-5322. [CrossRef]

95. Cooper, J.; Ziegler, T. A density functional study of SN2 substitution at square-planar platinum(II) complexes. Inorg. Chem. 2002, 41, 6614-6622. [CrossRef] [PubMed]

96. Brauer, G. Handbook of Preparative Inorganic Chemistry; Academic Press: New York, NY, USA, 1985; Volume 5.

97. Sheldrick, G.M. SHELXT Integrated space-group and crystal-structure determination. Acta Cryst. 2015, A71, 3-8. [CrossRef] [PubMed]

98. Sheldrick, G.M. Crystal structure refinement with SHELXT. Acta Cryst. 2015, C71, 3-8.

99. Hübschle, C.B.; Sheldrick, G.M.; Dittrich, B. ShelXle: A Qt graphical user interface for SHELXL. J. Appl. Cryst. 2011, 44, 1281-1284. [CrossRef] [PubMed]

Sample Availability: A sample of the catalyst is not available from the authors.

(c) 2019 by the authors. Licensee MDPI, Basel, Switzerland. This article is an open access article distributed under the terms and conditions of the Creative Commons Attribution (CC BY) license (http:/ / creativecommons.org/licenses/by/4.0/). 